\title{
Fast simulators for satellite cloud optical centroid pressure retrievals; evaluation of OMI cloud retrievals
}

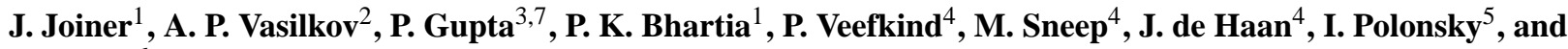 \\ R. Spurr 6 \\ ${ }^{1}$ Goddard Space Flight Center, Laboratory for Atmospheres, Greenbelt, MD, USA \\ ${ }^{2}$ Science Systems and Applications Inc., Lanham, MD, USA \\ ${ }^{3}$ University of Maryland, Baltimore County, Baltimore, MD, USA \\ ${ }^{4}$ Royal Dutch Meteorological Institute (KNMI), De Bilt, The Netherlands \\ ${ }^{5}$ Colorado State University, Ft. Collins, CO, USA \\ ${ }^{6}$ RTSolutions, Inc., Cambridge, MA, USA \\ ${ }^{7}$ Universities Space Research Association, Columbia, MD, USA \\ Correspondence to: J. Joiner (joanna.joiner@nasa.gov)
}

Received: 22 July 2011 - Published in Atmos. Meas. Tech. Discuss.: 5 October 2011

Revised: 19 January 2012 - Accepted: 4 March 2012 - Published: 8 March 2012

\begin{abstract}
The cloud Optical Centroid Pressure (OCP) is a satellite-derived parameter that is commonly used in tracegas retrievals to account for the effects of clouds on nearinfrared through ultraviolet radiance measurements. Fast simulators are desirable to further expand the use of cloud OCP retrievals into the operational and climate communities for applications such as data assimilation and evaluation of cloud vertical structure in general circulation models. In this paper, we develop and validate fast simulators that provide estimates of the cloud OCP given a vertical profile of optical extinction. We use a pressure-weighting scheme where the weights depend upon optical parameters of clouds and/or aerosols. A cloud weighting function is easily extracted using this formulation. We then use fast simulators to compare two different satellite cloud OCP retrievals, from the Ozone Monitoring Instrument (OMI), with estimates based on collocated cloud extinction profiles from a combination of CloudSat radar and MODIS visible radiance data. These comparisons are made over a wide range of conditions to provide a comprehensive validation of the OMI cloud OCP retrievals. We find generally good agreement between OMI cloud OCPs and those predicted by CloudSat. However, the OMI cloud OCPs from the two independent algorithms agree better with each other than either does with the estimates from CloudSat/MODIS. Differences between OMI cloud OCPs and those based on CloudSat/MODIS may result
\end{abstract}

from undetected snow/ice at the surface, cloud 3-D effects, cases of low clouds obscurred by ground-clutter in CloudSat observations and by opaque high clouds in CALIPSO lidar observations, and the fact that CloudSat/CALIPSO only observes a relatively small fraction of an OMI field-of-view.

\section{Introduction}

Information about the abundances of many chemically- and radiatively-active trace gases is retrieved using satellite solar backscatter instruments that make measurements at nearinfrared (NIR) through ultraviolet (UV) wavelengths. These trace-gas retrieval algorithms commonly require information about the mean photon path length in the atmosphere to properly account for the presence of clouds and aerosol. One way to express photon path length information is the so-called cloud optical centroid pressure (also known as the effective cloud pressure), or cloud OCP, that is defined as the characteristic pressure of a single cloud layer within the context of a particular cloud model. The word "optical" in OCP is used to distinguish it from the common mass centroid.

Several different algorithms make use of cloud OCPs or similar quantities to supplement and improve retrieved information about $\mathrm{O}_{3}$, including estimates of the total column (e.g., Coldewey-Egbers et al., 2005; van Roozendael et al.,

Published by Copernicus Publications on behalf of the European Geosciences Union. 
2006; Veefkind et al., 2006) and tropospheric concentrations (e.g., Ziemke et al., 2009; Joiner et al., 2009). Other studies have focused on various aspects of cloud-related errors on $\mathrm{O}_{3}$ retrievals (e.g., Koelemeijer et al., 1999; Vasilkov et al., 2004; Kokhanovsky et al., 2007b; Joiner et al., 2006).

Cloud OCPs have also been used in other trace-gas retrievals such as those for $\mathrm{NO}_{2}$ (e.g., Bucsela et al., 2006) and $\mathrm{CO}_{2}$ (e.g., Reuter et al., 2010) and cloud-related errors have been investigated (e.g., Boersma et al., 2004). In addition, cloud OCPs have been used for other applications such as short-wave flux calculations (Joiner et al., 2009; Vasilkov et al., 2009) and detection of multi-layer clouds and/or information about cloud vertical structure (e.g., Rozanov and Kokhanovsky, 2004; Rozanov et al., 2004; Joiner et al., 2010).

The instruments used for cloud OCP retrievals include the Global Ozone Monitoring Experiments (GOME and GOME2) (Burrows et al., 1999; Munro et al., 2006). The first GOME flew on the European Space Agency's (ESA's) European Remote Sensing 2 (ERS-2) launched in 1995. GOME-2 instruments are currently flying on the European Meteorological Satellite Operational (EUMetSat's MetOp) series of satellites. The SCanning Imaging Absorption SpectroMeter for Atmospheric CHartographY (SCIAMACHY) (Bovensmann et al., 1999) on ESA's Environmental Satellite (EnviSat) launched in 2002, makes spectral measurements from UV to NIR wavelengths. In addition, the Ozone Monitoring Instrument (OMI) (Levelt et al., 2006), flying on the (US) National Aeronautics and Space Administration's (NASA's) Aura satellite since 2004, measures backscattered spectra in the UV and visible.

There are several different remote sensing techniques that have been used to retrieve cloud OCPs or related information about cloud vertical structure such as the cloud-top and cloud-base pressure or cloud geometrical thickness assuming vertically uniform clouds (Ferlay et al., 2010; Rozanov and Kokhanovsky, 2004; Rozanov et al., 2004). These approaches include rotational-Raman (RR) scattering in the UV (Joiner and Bhartia , 1995; Joiner et al., 2004), oxygen dimer $\left(\mathrm{O}_{2}-\mathrm{O}_{2}\right)$ absorption near $477 \mathrm{~nm}$ (Acarreta et al., 2004; Sneep et al., 2008), and absorption in the $\mathrm{O}_{2}-\mathrm{A}$ band near $760 \mathrm{~nm}$ (e.g., Koelemeijer et al., 2001, 2002; Vanbauce et al., 2003; Kokanovsky et al., 2006). The $\mathrm{O}_{2}-\mathrm{A}$ band has also been used to retrieve information about aerosol plume height (e.g., Dubuisson et al., 2009).

Cloud OCP errors have been calculated from retrieval theory and radiative transfer calculations (e.g., Koelemeijer et al., 2001; Acarreta et al., 2004; Daniel et al., 2003; Vasilkov et al., 2008). For example, Vasilkov et al. (2008) showed that errors in the OMI can be large when the cloud optical thickness drops below 5. Several other studies have evaluated various satellite cloud OCP retrievals. Sneep et al. (2008) intercompared three different cloud OCP data sets from the A-train constellation of satellites. Correlations between these data sets were generally high (between 0.8 and 0.92) and within expectations of instrument and algorithm performance, though several systematic differences were noted. While some of these differences have been resolved in updated and reprocessed versions of the data sets, others remain unexplained. In another evaluation approach, Vasilkov et al. (2008) compared cloud OCPs with collocated data from the CloudSat radar and the Aqua MODerateresolution Imaging Spectrometer (MODIS) using radiative transfer calculations. It was shown that cloud OCPs from the OMI rotational-Raman algorithm captured variability depicted by CloudSat/MODIS. However, only a few samples were compared in that study.

Here, we formulate fast simulators that use cloud/aerosol extinction profiles as inputs to generate estimates of cloud/aerosol OCPs. We provide a method for estimating these quantities using a pressure-weighting scheme where the weights depend upon optical parameters of clouds and/or aerosols. One advantage of this formulation is that it is straightforward to extract a cloud weighting function.

The fast OCP simulators we develop here have several potential applications that may expand the use of satellite cloud OCP retrievals into the climate modeling and operational weather forecasting communities. For example, fast OCP simulators would be desirable for use of cloud OCP retrievals in data assimilation. Fast simulators could also enable the use of satellite cloud OCP retrievals for evaluation of cloud vertical structure in general circulation models. However, we must establish confidence in the satellite OCP retrievals and fast simulators as a prerequisite for their use in these applications. Here, we use the fast simulators for a comprehensive evaluation of OMI cloud OCP retrievals using collocated CloudSat/MODIS data over a wide range of conditions. A number of different types of cloud measurements made from the A-train constellation of satellites enabled this unique validation exercise.

The paper is structured as follows: Sect. 2 describes the satellite data sets used here. Sections 3 and 4 detail the formulation of full and fast OCP retrieval simulators, respectively. The fast OCP simulators are applied to CloudSat/MODIS data and compared with two OMI OCP retrievals in Sect. 5. Conclusions are given in Sect. 6.

\section{Satellite data sets}

In this work, we make use of several data sets from the Atrain constellation of satellites. These satellites fly in formation in polar orbits, crossing the equator within $15 \mathrm{~min}$ of each other near 13:30 LT (local time).

\subsection{OMI cloud OCP data sets}

We examine two types of cloud OCP retrievals from OMI. OMI is a spectrometer that makes Earth and solar measurements at UV and visible wavelengths from $270-500 \mathrm{~nm}$ with 
a spectral resolution of approximately $0.5 \mathrm{~nm}$ (Levelt et al., 2006). Its ground footprint varies; near nadir, it is approximately $12 \mathrm{~km}$ along the satellite track and $24 \mathrm{~km}$ across the $2600 \mathrm{~km}$ track. The footprint size increases towards the swath edge.

There are two independent approaches to retrieve cloud OCP from OMI that are summarized in Stammes et al. (2008). These algorithms make use of the basic property that clouds shield the atmosphere below them from atmospheric scattering and absorption, thus reducing photon pathlengths. The retrievals rely upon physical effects produced by wellmixed, well-characterized atmospheric constituents, namely absorption by oxygen and Raman scattering by both oxygen and nitrogen molecules.

Both OMI cloud algorithms use a simplified model to account for the complex effects of clouds on observed radiances. This approach, sometimes referred to as the Mixed Lambertian Equivalent Reflectivity (MLER) model, represents an observed satellite field-of-view (FOV) radiance $\left(I_{\text {obs }}\right)$ as a weighted combination of clear and cloudy subpixel radiances, $I_{\mathrm{clr}}$ and $I_{\mathrm{cld}}$, respectively, i.e.,

$I_{\mathrm{obs}}=\left(1-f_{\mathrm{eff}}\right) I_{\mathrm{clr}}+f_{\mathrm{eff}} I_{\mathrm{cld}}$,

(McPeters et al., 1996; Koelemeijer et al., 1999) where the weighting factor, $f_{\text {eff }}$, is known as the effective cloud fraction. The model accounts for partial cloud cover and scattering and absorption beneath thin clouds by representing the cloudy portion of the FOV, $I_{\text {cld }}$, as a Lambertian surface with a reflectivity of 0.8 ; since most clouds have a reflectivity of less than 0.8 , it follows that $f_{\text {eff }}$ is less than the geometrical cloud fraction $f_{\mathrm{g}}$. Justifications of 0.8 as the cloud reflectivity and other details of the MLER model are given in Koelemeijer et al. (1999), Ahmad et al. (2004), and Stammes et al. (2008). Theoretical simulations by Acarreta et al. (2004) and Vasilkov et al. (2008) suggest that cloud OCP errors should be approximately $50 \mathrm{hPa}$ or less for a wide range of typical viewing conditions and for moderate to high values of either $f_{\text {eff }}$ or cloud optical thickness. The main method of evaluating cloud OCPs post launch has been comparison of the two retrievals with one another. Sneep et al. (2008) showed that for $f_{\text {eff }}>0.5$, the mean difference between the two OMI cloud OCP retrievals was $44 \mathrm{hPa}$ and the standard deviation was $65 \mathrm{hPa}$, generally consistent with the predicted errors.

\subsubsection{OMI $\mathrm{O}_{2}-\mathrm{O}_{2}$ product}

The OMI $\mathrm{O}_{2}-\mathrm{O}_{2}$ algorithm, henceforth referred to as OMI $\mathrm{O} 2-\mathrm{O} 2$, makes use of the collision-induced absorption $\left(\mathrm{O}_{2}\right.$ $\mathrm{O}_{2}$ ) band at $477 \mathrm{~nm}$. This is the strongest oxygen absorption feature within the OMI wavelength range. The algorithm uses the Differential Optical Absorption Spectroscopy (DOAS) approach to determine a slant column amount of $\mathrm{O}_{2}-\mathrm{O}_{2}$ and continuum reflectance from OMI reflectances between $460 \mathrm{~nm}$ and $490 \mathrm{~nm}$ in OMI's visible channel. The algorithm uses a table-lookup approach to compute $f_{\text {eff }}$ and cloud OCP. Details of the approach are given in Acarreta et al. (2004), Sneep et al. (2008), and Stammes et al. (2008). The table lookup scheme has been modified recently by incorporating additional nodes and using reflectance as one of the axes instead of sun-normalized radiance. We use the latest available version of the algorithm here (V1.2.3.3).

\subsubsection{OMI RRS product}

The OMI rotational-Raman (RRS) algorithm makes use of the filling-in of solar Fraunhofer lines by rotational-Raman scattering (RRS) to determine the cloud OCP. This algorithm uses wavelengths between 345 and $355 \mathrm{~nm}$ in OMI's UV-2 detector to fit the high-frequency spectral structure of the solar-normalized radiance produced by the fillingin/depletion effect of RRS as described in Joiner and Bhartia (1995), Joiner et al. (2004), Joiner and Vasilkov (2006), and Vasilkov et al. (2008). It uses a wavelength not significantly affected by RRS $(354.1 \mathrm{~nm})$ to determine $f_{\text {eff. }}$. A wavelength shift between Earth and solar spectra is also determined. A soft-calibration approach that uses data over the Antarctic plateau corrects for artifacts in the individual detector elements that produced a so-called "striping effect" that was present from the beginning of the data record.

Modifications to the algorithm following the validation work of Vasilkov et al. (2008) include the use of a monthly surface albedo climatology over land and a Cox-Munk (Cox and Munk, 1954) treatment of the ocean surface scattering based on a mean surface wind speed of $6 \mathrm{~m} \mathrm{~s}^{-1}$ in conjunction with a water-leaving radiance monthly climatology. Both the surface albedo and water-leaving radiance climatologies are provided at $1^{\circ}$ latitude $\times 1^{\circ}$ longitude resolution, and they are based on $360 \mathrm{~nm}$ data from the Total Ozone Mapping Spectrometer (TOMS) (C. Ahn, personal communication, 2009). The version of the OMI RRS cloud algorithm used here is 1.8.3.

\subsection{CloudSat/MODIS 2B TAU and 2B-GEOPROF-LIDAR products}

We make use of cloud extinction profile retrievals known as the CloudSat 2B-TAU product (Cloudsat, 2008). Extinction profiles are estimated using the $94 \mathrm{GHz}$ CloudSat Cloud Profiling Radar (CPR) reflectivity measurements (Stephens et al., 2008) and radiances from the Aqua MODIS instrument. The CloudSat measurements are made as a function of altitude. When comparing with OMI retrievals, we use the CloudSat 2B GEOPROF data set, based on information from the European Center for Medium-range Weather Forecasts (ECMWF), to provide the 2B TAU extinction profiles as a function of pressure. All CloudSat data sets used here are from revision 4 .

It is well known that CloudSat does not detect all clouds due to either low radar sensitivity or the presence of ground clutter (L'Ecuyer et al., 2008; Stephens et al., 2008). For 
example, thin cirrus that falls below the minimum detectable level of the CPR may be missed by CloudSat, while these clouds are clearly shown by lidar observations from the Cloud-Aerosol Lidar and Infrared Pathfinder Satellite Observation (CALIPSO) that is flying in formation with CloudSat. In addition, low clouds may be obscured by ground clutter in CloudSat observations. It is also difficult to interpret CloudSat data when both liquid and ice are present in the same vertical bin. L'Ecuyer et al. (2008) showed that the effect of undetected cirrus is far less serious than missed low clouds for estimates of top-of-the-atmosphere short-wave (TOA$\mathrm{SW})$ radiative flux. All of these situations lead to uncertainties in the derived 2B-TAU extinction profiles and consequently in calculations of cloud OCP based on this product. While some of these missed clouds are seen using the combined CloudSat-CALIPSO cloud mask product, known as 2B-GEOPROF-LIDAR (Mace et al., 2009), that product does not provide cloud extinction information needed for cloud OCP calculations. We use the 2B-GEOPROF-LIDAR product for quality control of the 2B-TAU product as described below. We note that the 2B-GEOPROF-LIDAR product will not detect all missed low clouds, because the lidar is not able to penetrate all high-level clouds that may obscure low level clouds.

\subsection{MODIS cloud top pressure}

We collocated MODIS cloud-top pressure retrievals (Menzel et al., 2008) from collection 5 with OMI FOVs as described by Joiner et al. (2010). Cloud-top pressures are retrieved with MODIS thermal IR channels by the $\mathrm{CO}_{2}$ slicing approach for high clouds or with the window channel brightness temperature for lower clouds at $(5 \mathrm{~km})^{2}$ resolution. Menzel et al. (2008) state that a reliable MODIS cloud-top pressure retrieval is possible for integrated optical depths greater than unity, noting that MODIS detects the radiative mean of cirrus clouds in the $\mathrm{CO}_{2}$ bands that is frequently more than $1 \mathrm{~km}$ inside the cloud as determined by lidar measurements. For each OMI FOV, we save the minimum, maximum, mean, and standard deviation of the cloud top pressure and other cloud parameters derived from MODIS.

\subsection{Quality control including removal of inhomogeneous OMI observations}

OMI rotational-Raman cloud pressure retrievals are not performed when $f_{\text {eff }}<5 \%$. This happens not only when geometrical cloud fractions are small, but also for cases when the geometrical cloud fraction may be large but the optical thickness is low, such as optically thin cirrus. Therefore, $f_{\text {eff }}$ must be greater than $5 \%$ for a successful collocation. Because OMI errors can be large for low cloud optical thicknesses $(\tau)$, here we include only OMI FOVs for which the averaged MODIS $\tau>5$. This check also eliminates situations of vertically-isolated thin cirrus that may be missed by
CloudSat, ensuring that we include only situations of moderate $\tau$ in conjunction (beneath) optically thin cirrus. We remove OMI FOVs where the solar zenith angle (SZA) $>80^{\circ}$.

As in Joiner et al. (2010), we attempt to remove situations where the CloudSat profiles may not be representative of the much larger OMI FOV. The nadir-viewing CloudSat has only a single field-of-view of width approximately $1.4 \mathrm{~km}$ across the satellite track as compared with OMI's $24 \mathrm{~km}$ width. Therefore, the CloudSat slice along the satellite track samples only a small fraction of an OMI FOV. Here, we eliminated FOVs for which the MODIS cloud-top pressure standard deviation within the OMI FOV was greater than $100 \mathrm{hPa}$.

It should be noted that a lack of cloud-top pressure variability does not necessarily indicate that an OMI FOV is homogeneous with respect to the cloud OCP, because cloudtop pressure does not predict variability in cloud vertical structure below the top (Joiner et al., 2006). Therefore, we also used CloudSat itself along with our fast simulator, described below, to check for inhomogeneity of the cloud OCP along track within OMI FOVs. We eliminate observations for which the along-track CloudSat-simulated OCP had a standard deviation $>100 \mathrm{hPa}$, indicating an inhomogeneous OMI FOV. To determine the variability of either MODIS cloud-top pressure or CloudSat-estimated OCP data within an OMI FOV, we consider only valid pixels where clouds exist. We are then able to use these checks effectively in partially-cloudy conditions. For example, if the fraction of cloudy MODIS elements within an OMI FOV is $50 \%$ and the variability of cloud-top pressure is small for those elements, then the pixel will not be excluded by the MODIS inhomogeneity check.

In addition to the homogeneity checks, we use the 2BGEOPROF-LIDAR to check for cases of missed low-level clouds in the 2B-TAU product. We remove an OMI FOV if the maximum cloud fraction from the collocated 2BGEOPROF-LIDAR product $>10 \%$ for layers within $400 \mathrm{hPa}$ of the surface and the total $\tau$ for those layers from the 2BTAU product $<5$.

\section{Full rotational-Raman retrieval simulator $\left(\mathbf{R}^{3} \mathbf{S}\right)$}

We developed a full OMI rotational-Raman retrieval simulator (henceforth referred to as $\mathrm{R}^{3} \mathrm{~S}$ ) using radiative transfer calculations carried out with the generic discrete ordinate rotational-Raman scattering code, known as LIDORT-RRS (Spurr et al., 2008). $\mathrm{R}^{3} \mathrm{~S}$ was used by Vasilkov et al. (2008) to compute errors in the OMI rotational-Raman (RRS) scattering cloud OCP retrieval. In that study, it was also used to simulate cloud OCP from CloudSat/MODIS 2B-TAU extinction profiles for a few soundings in a deep convective complex. These simulations were then compared with OMI RRS retrievals. 
As inputs for $\mathrm{R}^{3} \mathrm{~S}$ in this study, we again simulate satellite cloudy-sky radiances based on CloudSat 2B-TAU profiles using plane-parallel clouds. We performed three separate simulations using different cloud phase functions. The first of these is the water-droplet $\mathrm{C} 1$ cloud model with a modifiedgamma size distribution with an effective radius of $6 \mu \mathrm{m}$ (Deirmendjian, 1969). The second is a Henyey-Greenstein (H-G) phase function with asymmetry factor $g=0.85$. Third, we use a shortwave model of ice clouds with an effective diameter of $30 \mu \mathrm{m}$ (Baum et al., 2005). In all cases, the cloud single scattering albedo was set to unity. We found that the phase function had a very small effect on the simulated cloud OCPs for $\tau>5$. Our focus in this work is on cases where $\tau>5$. For these cases, we find that the ice cloud model produces cloud OCPs on average $23 \mathrm{hPa}$ higher than those simulated using the $\mathrm{C} 1$ model with $\sigma=31 \mathrm{hPa}$. Similarly the $\mathrm{H}-\mathrm{G}$ cloud OCPs are about $22 \mathrm{hPa}$ higher than those from the $\mathrm{C} 1$ model with $\sigma=28 \mathrm{hPa}$. Since these differences are not large, all subsequent results use the $\mathrm{C} 1$ cloud model exclusively.

For both forward and inverse calculations, the Earth's surface is assumed to be Lambertian at a pressure of $1013 \mathrm{hPa}$ with a reflectivity of 0.05 . The value of the assumed surface reflectivity is not of great importance for the simulations in this paper as long as reasonable values are used; however, it is of critical importance that the values assumed in both forward and inverse calculations are consistent to prevent errors from being introduced into the simulation.

As described in Vasilkov et al. (2008), the effects of rotational-Raman scattering are simulated at a single wavelength while $f_{\text {eff }}$ is derived at a second wavelength. A simple table-lookup retrieval scheme is then performed using simulated data at those wavelengths. Data are simulated for the OMI viewing geometry corresponding to a given CloudSat location.

Here, we extend the work of Vasilkov et al. (2008) comparing $\mathrm{R}^{3} \mathrm{~S}$ with OMI RRS retrievals for several thousand CloudSat 2B-Tau profiles taken over a single day under a wide range of conditions with SZA $<70^{\circ}$. To minimize the amount of computations performed in $\mathrm{R}^{3} \mathrm{~S}$, we averaged the layer optical thicknesses of all CloudSat soundings falling within a given OMI FOV. This provides a single optical extinction profile for each OMI FOV. The effect of this averaging is discussed in more detail in Sect. 5.

Figure 1 shows a comparison of the $\mathrm{R}^{3} \mathrm{~S}$-generated cloud OCP with OMI RRS cloud OCP retrievals. We used 2972 CloudSat 2B-TAU profiles from 13 November 2006 for this comparison. Note that the 2B-GEOPROF-LIDAR product was not available on this day, so the check for missed low-level clouds is not performed in this comparison or in the similar comparison with a fast simulator in Sect. 4.3. There is generally good agreement, although OMI RRS retrievals are biased low by approximately $75 \mathrm{hPa}$ for high pressure (low altitude) clouds that dominate the population. There is also a branch of OMI RRS retrievals with higher OCPs than those

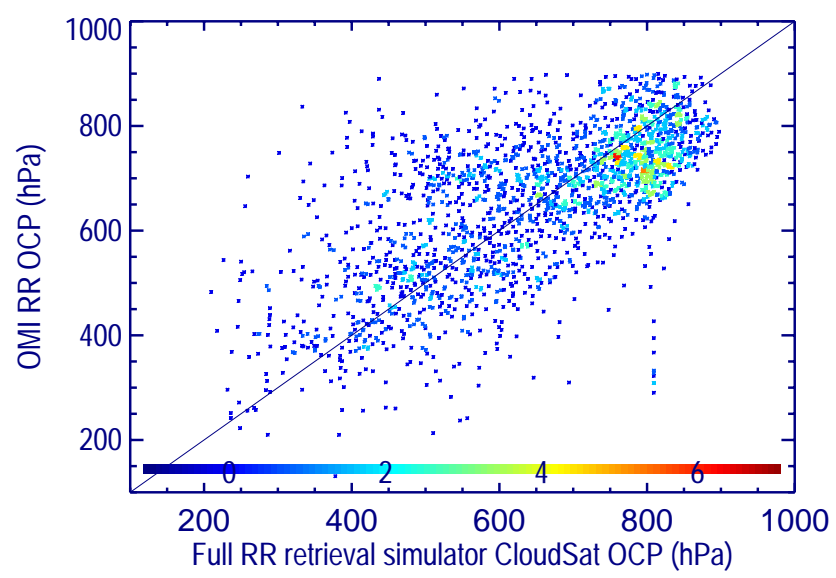

Fig. 1. Two dimensional (2-D) histogram comparing cloud OCPs from the OMI rotational-Raman scattering retrievals with those from the full rotational-Raman scattering simulator $\left(\mathrm{R}^{3} \mathrm{~S}\right)$ using CloudSat extinction profiles with $\tau>5$ for a single day (13 November 2006). Results are provided as 2 dimensional densities in cloud pressure bins of $10 \mathrm{hPa}$. The color scale represents the number of observations falling within a given bin.

from the $\mathrm{R}^{3} \mathrm{~S}$ CloudSat simulation. We examine these situations in more detail below.

\section{Fast cloud optical centroid pressure (OCP) simulators}

\subsection{Cloud OCP formulations}

The cloud OCP, within the context of the LambertianEquivalent Reflectivity (LER) model, is defined as the pressure at which a Lambertian surface is placed to provide the observed amount of absorption (e.g., from oxygen) or fillingin due to rotational-Raman scattering. The Mixed LER (MLER) model further specifies a weighting of clear and cloudy subpixels with the effective cloud fraction as given by Eq. (1). The resulting cloud pressure, $P_{\mathrm{OCP}}$, can be used to approximate the mean photon pathlength of a more complex scenario in which there could be partial or thin clouds and the clouds themselves may be geometrically thick and inhomogeneous (e.g., Koelemeijer et al., 2001; Vasilkov et al., 2008; Stammes et al., 2008; Ziemke et al., 2009).

The mean or centroid "optical pressure" of a complex cloud can be estimated using the relative contributions to e.g., rotational-Raman scattering or $\mathrm{O}_{2}\left(\mathrm{O}_{2}-\mathrm{O}_{2}\right)$ absorption from all scattering layers. Consider a simple scenario for a cloud OCP retrieval making use of a pressure- and temperatureindependent absorber with a constant mixing ratio in an atmosphere with no Rayleigh scattering. In a well-mixed layer, the column amount of the absorbing gas is proportional to the layer pressure thickness $\Delta P$. Absorption in the atmospheric layer is proportional to the column amount of the absorber. It follows that satellite-observed radiance backscattered from 
a cloud layer $L$ at a mean pressure $P_{L}$ undergoes an amount of absorption that is proportional to $\Delta P_{L}$, where $\Delta P_{L}$ is the layer thickness from the top of the atmosphere $\left(P_{0}=0\right)$ to pressure $P_{L}\left(\Delta P_{L}=P_{L}\right)$.

For a given cloud or aerosol optical extinction profile, one may compute cloud/aerosol layer reflectances and transmittances, $r_{L}$ and $t_{L}$, respectively, from a layer $L$ using, for example, a two-stream model. Here, we use the deltaEddington approximation of Joseph et al. (1976) with diffuse illumination to compute the layer reflectances and transmittances from elastic scattering (rotational-Raman scattering is not included). The delta-Eddington approximation provides accurate reflectances and transmittances over a wide range of conditions (errors $<2 \%$ for SZA $<$ about $66^{\circ}$ increasing to a maximum of $15 \%$ as SZA approaches $84^{\circ}$ ). Errors will be smaller for geometrically thick clouds where the dependence upon SZA is mitigated as light becomes more diffuse inside the cloud. The delta-Eddington approximation therefore appears to be appropriate for providing relative values of layer reflectances and transmittances (with respect to one another) that are most important for estimating the cloud OCP.

We then compute a reflectance contribution, $\rho_{L}$, from layer $L$ to the total cumulative reflectance using

$\rho_{L}=\frac{r_{L} T_{L-1}^{2}}{\left(1-R_{L-1} r_{L}\right)}$,

where $R_{L}$ and $T_{L}$ are cumulative reflectances and transmittances, respectively, from the top-of-atmosphere to layer $L$, given by

$R_{L}=\sum_{l=1}^{L} \rho_{l}$

and

$T_{L}=\frac{T_{L-1} t_{L}}{1-R_{L-1} r_{L}}$,

and $T_{0}=1, R_{0}=0$.

The cloud OCP $\left(P_{\mathrm{OCP}}\right)$ may then be approximated as a weighted-average over all layers from the top-of-atmosphere to the surface, where the weighting factor is given by $\rho_{L}$, i.e.,

$P_{\mathrm{OCP}} \simeq \frac{\sum_{l} \rho_{l} P_{l}}{\sum_{l} \rho_{l}}$.

This formulation would produce an observed amount of absorption weighted by the same factor, i.e., an amount of absorption equivalent to that obtained when a single geometrically-thin, optically-thick cloud layer is placed at a pressure of $P_{\mathrm{OCP}}$.

We tested several other methods for computing layer reflectances and transmittances such as those from Coakley and Chylek (1975) and Meador and Weaver (1980) with different input parameters. All methods provided very similar OCP values; although absolute reflectances and transmittances may be somewhat different for the different methods, the relative values as a function of layer, did not differ substantially. For example, correlation coefficients computed with respect to exact simulator calculations for the CloudSat profiles used in Sect. 3 varied within \pm 0.05 and biases within $\pm 20 \mathrm{hPa}$ for the suite of radiative transfer models and input parameters tested. We also compared OCPs computed with single scattering albedos of 1.0 and 0.99. Again, the relative values of layer reflectances/transmittances did not change enough to make significant differences (i.e., more than a few $\mathrm{hPa}$ ) in computed cloud OCPs.

The standard fast simulator may also be modified to account for properties of different types of cloud OCP retrievals. For example, the weighting scheme may be modified to simulate a cloud OCP from a retrieval based on an absorber with a pressure-squared dependence $\left(P_{\mathrm{OCP}}^{\prime}\right)$ such as the oxygen dimer, e.g.,

$P_{\mathrm{OCP}}^{\prime} \simeq \sqrt{\frac{\sum_{l} \rho_{l} P_{l}^{2}}{\sum_{l} \rho_{l}}}$.

We compared OCPs computed with the standard (Eq. 5) and pressure-squared (Eq. 6) formulations using profiles from one day of CloudSat data. We found that the pressuresquared formulation gave OCPs on average about $7 \mathrm{hPa}$ higher (lower altitude) than the standard formulation with a standard deviation of $11 \mathrm{hPa}$ and a maximum difference of $101 \mathrm{hPa}$.

\subsection{Comparison of fast and full cloud OCP simulators}

Figure 2 compares the standard fast simulator results with those from the full rotational-Raman retrieval simulator $\left(R^{3} S\right)$ for the same sample of CloudSat profiles used above in Fig. 1. The $\mathrm{R}^{3} \mathrm{~S}$ incorporates errors in the rotational-Raman cloud algorithm resulting from the use of the MLER model. Such errors have been previously reported by Vasilkov et al. (2008). These errors are largest for low cloud optical thicknesses $(<\sim 5)$. $R^{3} S$ results also account for the effects of enhanced photon pathlengths due to Rayleigh scattering within clouds and between cloud layers that are not accounted for with the fast simulator. Considering the simplicity of the fast simulator and the errors present in $\mathrm{R}^{3} \mathrm{~S}$, the agreement between the two is quite good, with a bias of $7.4 \mathrm{hPa}$, a standard deviation of $82 \mathrm{hPa}$, and a correlation coefficient of 0.89 .

\subsection{Single-day comparison of Cloudsat-based fast simulator with OMI RRS retrievals}

Figure 3 shows a comparison of OMI cloud RRS retrievals with the standard fast OCP simulator for the same sample used in comparisons with $\mathrm{R}^{3} \mathrm{~S}$ in Fig. 1. Here, we see a slightly larger bias for high pressure (low altitude) clouds as compared with $R^{3} S$. This is the result of a high bias in the fast simulator with respect to the full $\mathrm{R}^{3} \mathrm{~S}$ simulator as shown in 


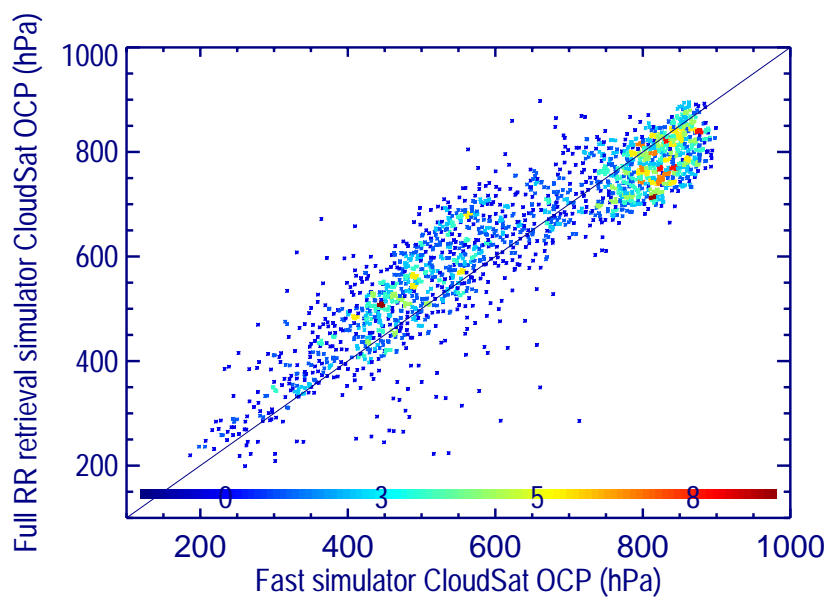

Fig. 2. 2-D histogram comparing cloud OCPs from the standard fast simulator with those from the full rotational-Raman scattering simulator $\left(\mathrm{R}^{3} \mathrm{~S}\right)$ for the same sample used in Fig. 1.

Fig. 2. $\mathrm{R}^{3} \mathrm{~S}$ should better simulate OMI cloud RRS retrievals including errors owing to the use of the MLER model. We also see larger biases in the opposite direction for the lower pressure clouds. Again, this is consistent with expected bias in the fast simulator with respect to $\mathrm{R}^{3} \mathrm{~S}$. Although the full $\mathrm{R}^{3} \mathrm{~S}$ provides a somewhat better agreement with OMI RRS retrievals than the fast simulator, the latter provides reasonable estimates of cloud OCP at a small fraction of the computational cost.

\subsection{Cloud OCP weighting functions}

In Eq. (5), $\rho$ can be physically interpreted as a pressure weighting function. In other words, it weights a layer $L$ with mean pressure $P_{L}$ by the reflectance contribution from that layer, $\rho_{L}$. Next, we examine weighting functions calculated for one of the cloud scenarios used by Sneep et al. (2008) to investigate the behavior of four different cloud OCP algorithms; both the OMI RRS and $\mathrm{O}_{2}-\mathrm{O}_{2}$ algorithms were included as well as two $\mathrm{O}_{2}$-A band algorithms. In this example, the cloud is located between 550 and $800 \mathrm{hPa}$. As in Sneep et al. (2008), we use two different total cloud optical thicknesses, $\tau=9$ and 42 , where the optical thickness is equally distributed within the cloud. Sneep et al. (2008) showed that all algorithms produced OCPs near the geometric center of the cloud. For SZAs of $30^{\circ}$ and $40^{\circ}$, view zenith angle (VZA) of $30^{\circ}$, and relative azimuth angle of $90^{\circ}$, cloud OCPs were slightly higher for $\tau=9$ as compared with $\tau=42$. For higher SZAs and VZAs, differences between the $\tau=9$ and 42 cases were smaller.

Figure 4 shows examples of weighting functions produced for the above scenarios along with the cloud OCPs produced by the standard fast simulator. For both cloud optical thicknesses, the fast simulator places the cloud OCP in the middle of the cloud similar to the full simulations shown in Sneep et

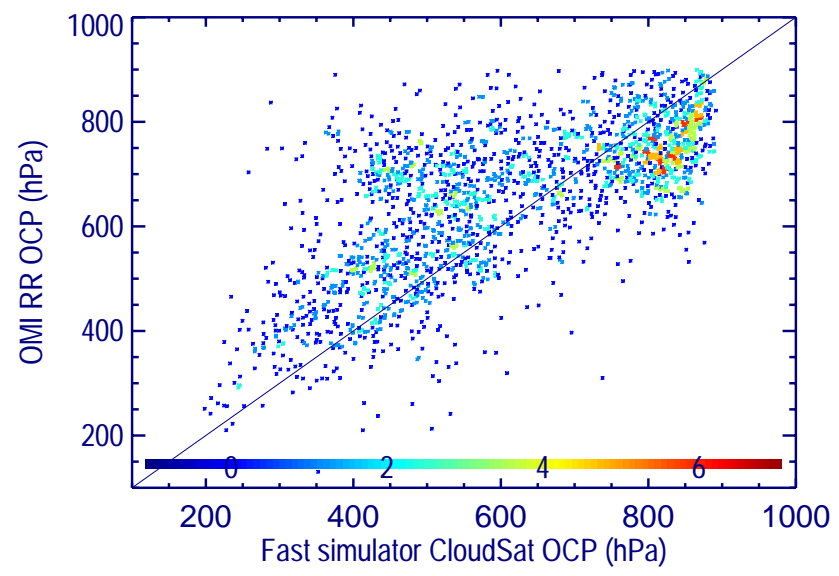

Fig. 3. Similar to Fig. 1 but comparing cloud OCPs from the OMI rotational-Raman retrievals with those from the standard fast simulator.

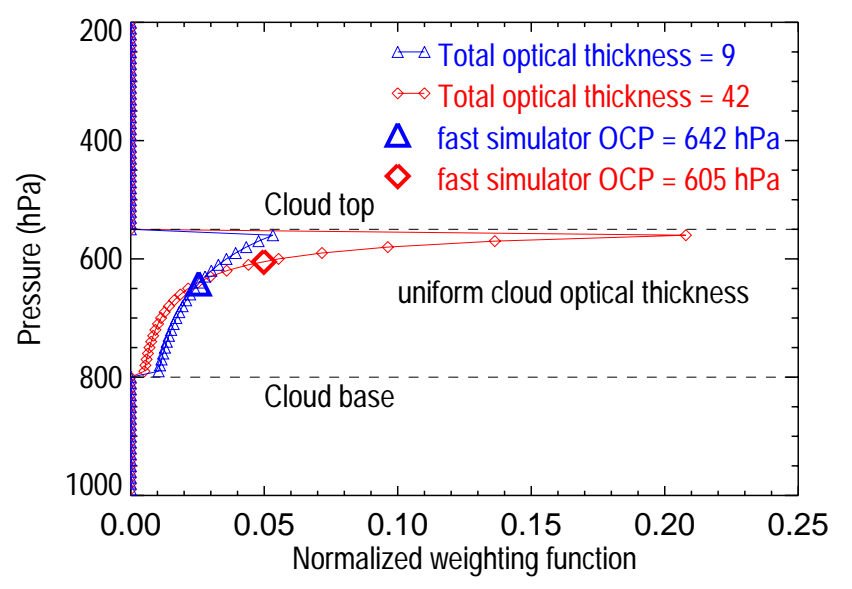

Fig. 4. Cloud OCPs and weighting functions for clouds with a uniform optical extinction profile and two different total optical thicknesses.

al. (2008). As expected, the fast simulator shows more photon penetration for the $\tau=9$ case. For the $\tau=42$ case, the fast simulator cloud OCP is weighted more towards the top part of the cloud.

Figures 5-6 show sample weighting functions and cloud OCP simulations for several extinction profiles from the CloudSat 2B-TAU product. Figure 5 shows examples where both fast simulators produce similar results as compared with those from $\mathrm{R}^{3} \mathrm{~S}$. In the first example, the OCPs are at a slightly higher pressure than the peaks of the weighting function and the extinction profile owing to contributions from below the peaks. In contrast, the second example shows a case where the OCP is at a lower pressure than the extinction and weighting function peaks; contributions from a thin cloud layer above the optically thicker lower level produce this behaviour. 

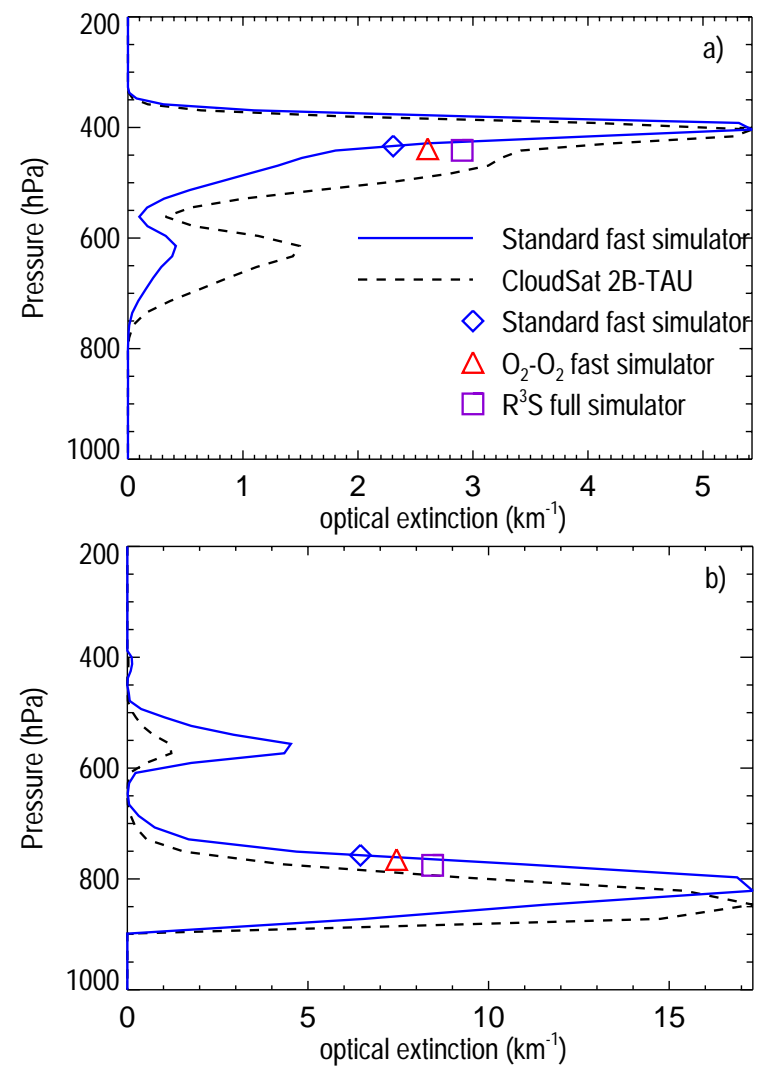

Fig. 5. Two examples of CloudSat cloud extinction profiles (dashed curves), corresponding cloud OCPs computed with different simulators (symbols as indicated, offset on the x-axis for clarity), and weighting functions computed using the standard fast simulator (blue solid curves).

Figure 6 shows examples where OCP differences between the fast simulators and $\mathrm{R}^{3} \mathrm{~S}$ are larger, and one case where the difference between standard and pressure-squared $\left(\mathrm{O}_{2}-\mathrm{O}_{2}\right)$ weighting in the fast simulators is also significant. The profile in Fig. 6a shows a case where the upper layer has a large optical thickness $(\sim 50)$. The cloud OCP weighting function peaks at a higher altitude than the cloud extinction profile. The standard fast cloud OCP simulation is close to the peak in the weighting function in the upper cloud deck; there is not much sensitivity of the cloud OCP to the lower cloud deck. The standard and pressure-squared weightings provide similar results in this case. The full $\mathrm{R}^{3} \mathrm{~S}$ cloud OCP simulation is almost $150 \mathrm{hPa}$ higher than the estimates from the fast simulators. This difference presumably results from enhanced photon pathlengths due to Rayleigh scattering within the cloud that is not accounted for in the fast simulators.

Figure $6 \mathrm{~b}$ shows an example where the standard and pressure-squared weightings provide slightly different results. This is another multi-layer cloud case, but here the top layer has a lower optical thickness $(\sim 6)$. As a result, the weighting function shows significant sensitivity to the lower cloud deck. As expected, the pressure-squared weighting
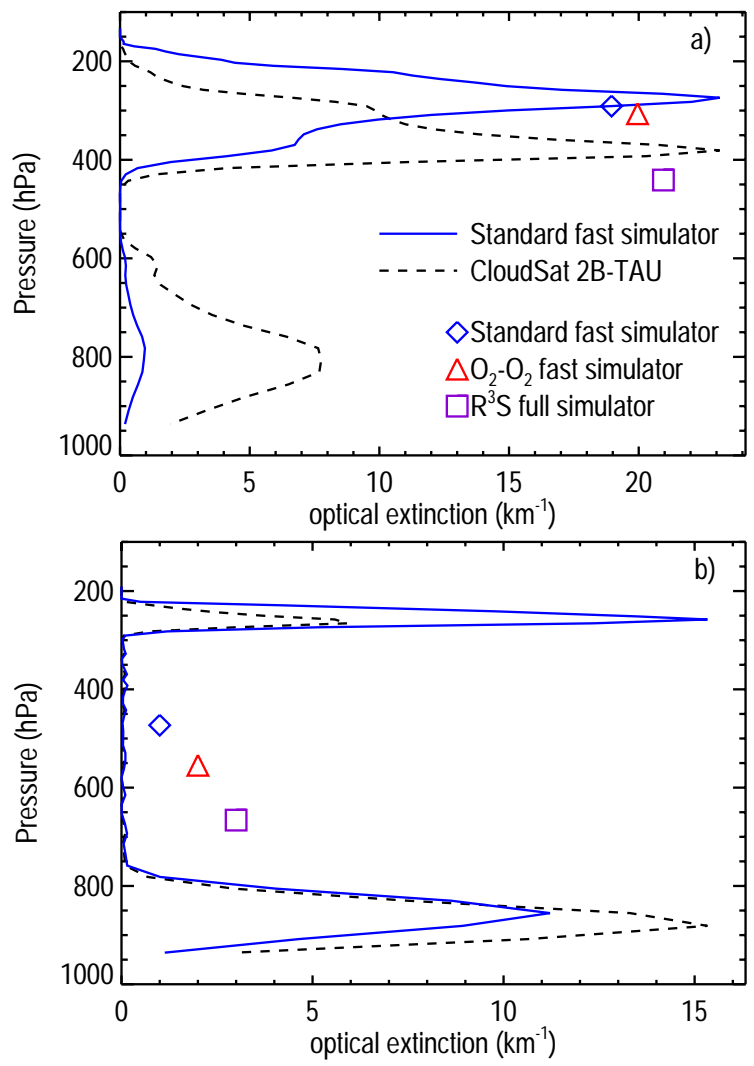

Fig. 6. Similar to Fig. 5; Two examples of CloudSat cloud extinction profiles for multi-layer clouds: (a) case with an optically thick upper layer ( $\tau \simeq 50$ ); (b) case with an optically thin upper layer ( $\tau \simeq 6$ ). Standard and $\mathrm{O}_{2}-\mathrm{O}_{2}$ fast simulator results are more similar for the optically thick upper layer; $\mathrm{O}_{2}-\mathrm{O}_{2}$ weights more heavily towards the lower layer when the upper layer is more optically thin.

provides more sensitivity to the lower cloud deck (higher pressure) than that from the standard weighting. Both fast cloud OCP simulations provide a value in the middle of the two cloud decks, with the pressure-squared weighting about $75 \mathrm{hPa}$ higher. The full $\mathrm{R}^{3} \mathrm{~S}$ provides a higher value of cloud OCP than both fast simulations, presumably because it accounts for Rayleigh scattering between the cloud layers.

\section{Monthly comparisons of CloudSat-based fast simulator OCPs with OMI retrievals}

The fast simulators make it more computationally feasible to do a large number of comparisons with CloudSat under a wide range of conditions. Such comparisons may reveal specific problems with the cloud OCP retrievals. However, in all comparisons of this type, we must bear in mind the expected differences between the fast simulators and the retrievals as shown for the RRS retrievals in Fig. 2.

Next, we compare CloudSat-based fast simulator cloud OCPs with retrievals from both OMI cloud algorithms for 

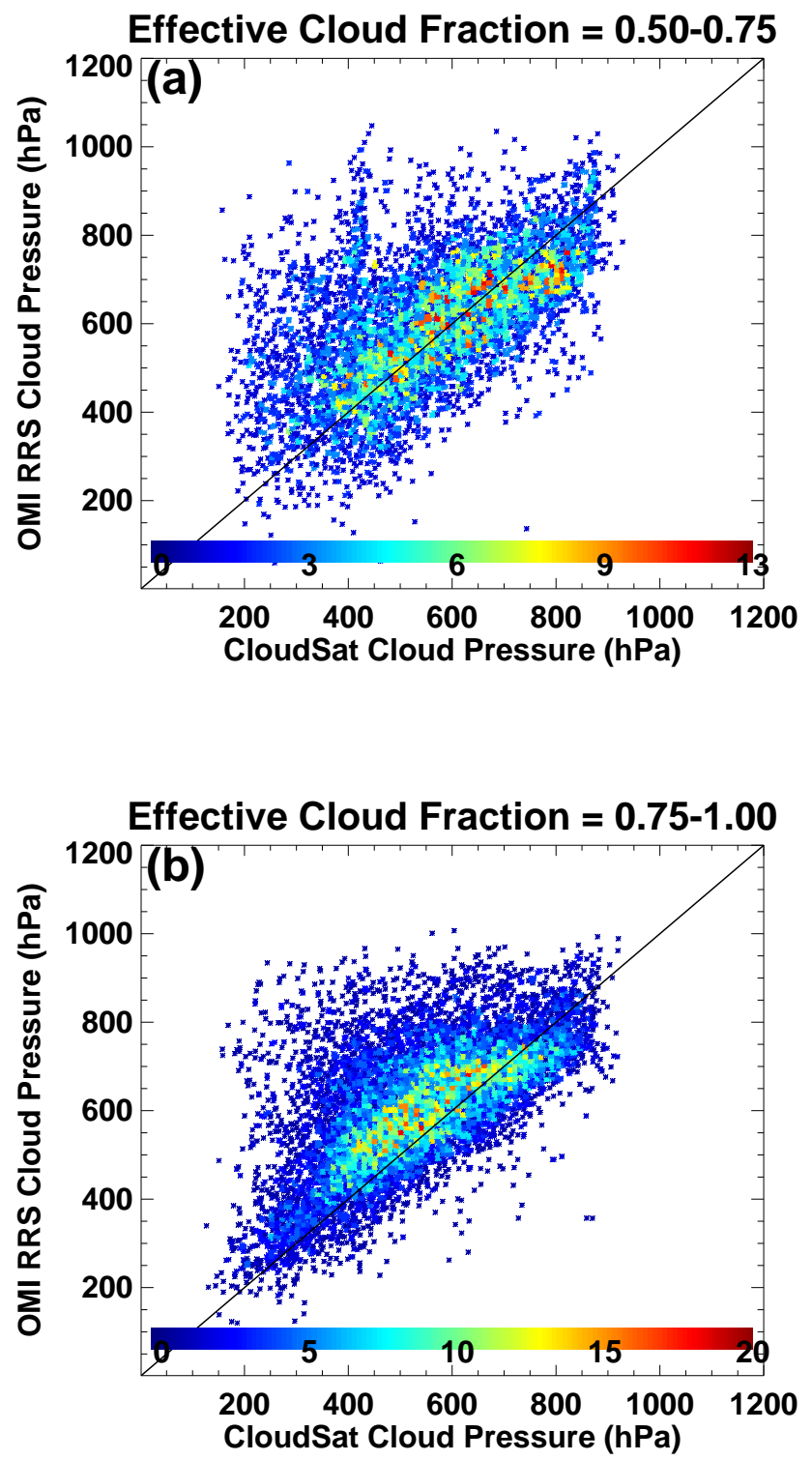

Fig. 7. Comparison of cloud pressures using a 2-D histogram as in Fig. 2: CloudSat OCPs (based on 2B-TAU profiles and the standard fast simulator) with OMI RRS cloud OCP retrievals over land for different bins of effective cloud fraction for July 2007. Note that the color scale changes for the different effective cloud fraction bins.

two months (January and July 2007). OMI RRS retrievals will be compared with results from the standard simulator and those from $\mathrm{O}_{2}-\mathrm{O}_{2}$ will be compared with results from the pressure-squared formulation. In this set of comparisons, we use a different scheme for averaging CloudSat data along the track for the length of the OMI FOV. Here, we compute a cloud OCP using our fast simulators (standard and pressuresquared versions) for each cloudy CloudSat sounding with total $\tau>0.1$ that falls within an OMI FOV. We then compute a reflectance-weighted average OCP over the corresponding CloudSat pixels. We believe this method to be more accurate
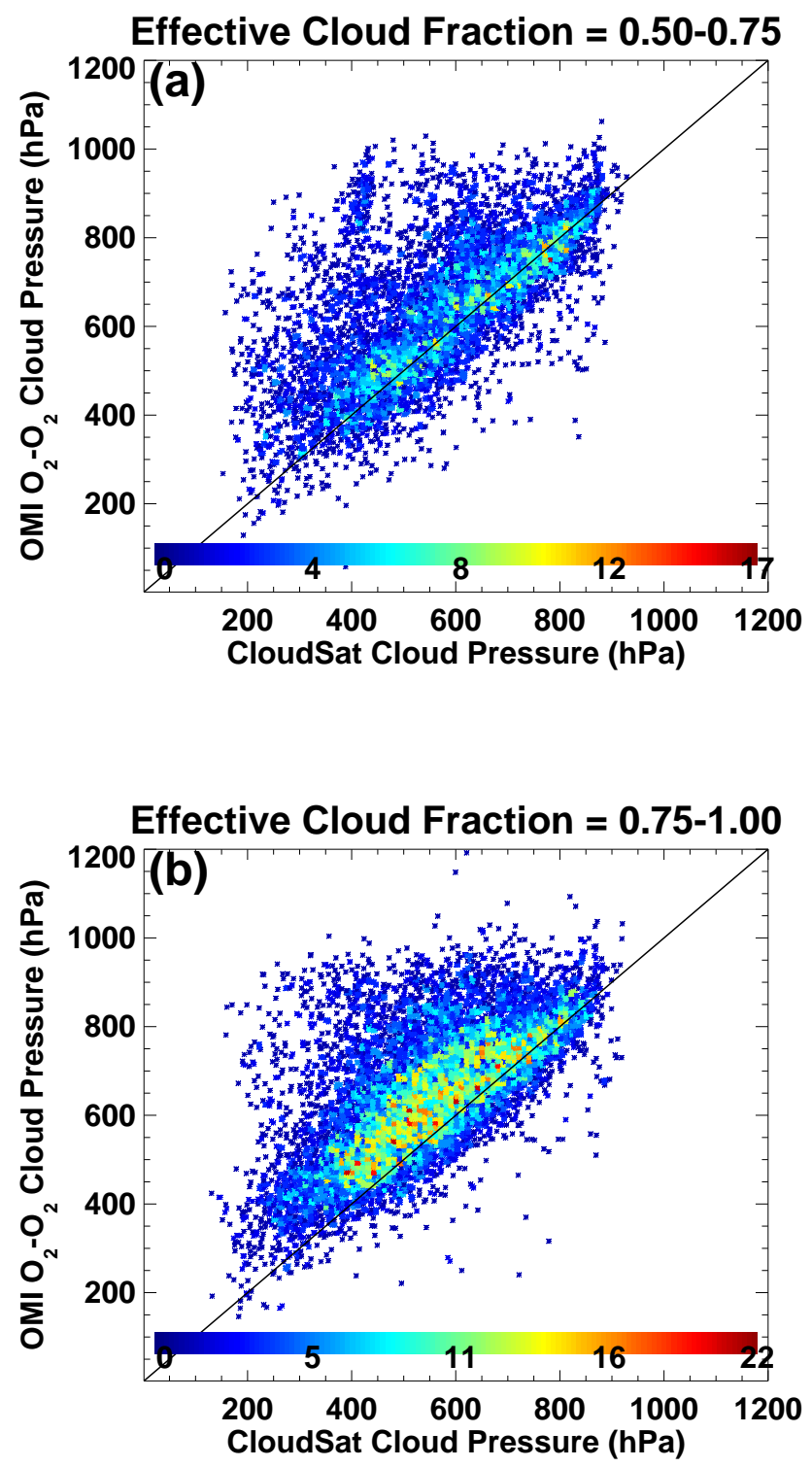

Fig. 8. Similar to Fig. 7 but for OMI $\mathrm{O}_{2}-\mathrm{O}_{2}$ cloud OCP retrievals (over land, July 2007).

than averaging optical thicknesses of CloudSat profiles over the length of the OMI pixel as was done in Sect. 3. Neverthe-less, differences between the two averaging methods are small; for a single day of CloudSat profiles with total optical thicknesses $>5$, the mean difference in cloud OCP was $3.6 \mathrm{hPa}$ with a standard deviation of $8.3 \mathrm{hPa}$.

\subsection{Comparisons with CloudSat-based fast simulators over land}

Figures 7-8 show comparisons between fast simulator CloudSat-based OCPs and the OMI RRS and $\mathrm{O}_{2}-\mathrm{O}_{2}$ cloud retrievals, respectively, over land for different bins of $f_{\mathrm{eff}}$ for July 2007. $f_{\text {eff }}$ is from the OMI RRS product and is 
Table 1. Monthly-mean cloud OCP comparison statistics including average(mean) difference, standard deviation of the difference $(\sigma)$, both in $\mathrm{hPa}$, and correlation coefficient, $R$, for July 2007, where CS stands for OCPs from CloudSat profiles run through the fast simulators.

\begin{tabular}{|c|c|c|c|c|c|c|}
\hline \multirow[b]{2}{*}{$\begin{array}{l}\text { Data sets, } \\
\text { conditions }\end{array}$} & \multicolumn{3}{|c|}{$0.50<f_{\text {eff }}<0.75$} & \multicolumn{3}{|c|}{$0.75<f_{\text {eff }}<1.0$} \\
\hline & $\begin{array}{l}\text { avg. } \\
\text { diff. }\end{array}$ & $\sigma$ & $R$ & $\begin{array}{l}\text { avg. } \\
\text { diff. }\end{array}$ & $\sigma$ & $R$ \\
\hline \multicolumn{7}{|l|}{ Land } \\
\hline RRS-CS & 41 & 143 & 0.59 & 72 & 122 & .64 \\
\hline $\mathrm{O}_{2} \mathrm{O}_{2}-\mathrm{CS}$ & 70 & 132 & 0.66 & 102 & 121 & .65 \\
\hline RRS-O ${ }_{2} \mathrm{O}_{2}$ & -33 & 87 & 0.84 & -36 & 62 & .90 \\
\hline \multicolumn{7}{|l|}{ Ocean } \\
\hline RRS-CS & 36 & 144 & 0.65 & 52 & 125 & .64 \\
\hline $\mathrm{O}_{2} \mathrm{O}_{2}-\mathrm{CS}$ & 59 & 143 & 0.68 & 68 & 128 & .65 \\
\hline $\mathrm{RRS}-\mathrm{O}_{2} \mathrm{O}_{2}$ & -28 & 86 & 0.86 & -24 & 62 & .92 \\
\hline
\end{tabular}

used for all subsequent figures to provide the same sample for comparisons and computed statistics. Statistics for these and other comparisons are provided in Table 1.

There is reasonable agreement between CloudSatsimulated OCPs and those from both OMI algorithms. Slight biases between CloudSat and OMI RRS OCPs resemble those shown earlier that are produced from inconsistencies between OMI retrievals and the fast simulators. However, as was also shown in Fig. 1, there is a cluster of retrievals with CloudSat-based OCPs near $400 \mathrm{hPa}$ for which both OMI algorithms retrieve significantly higher pressures. The differences are larger than those expected from the fast simulators.

The reduced scatter at higher effective cloud fractions can be explained as follows: Both random and systematic errors in the cloud OCP retrievals are amplified by a factor that is inversely proportional to the cloud radiance fraction $\left(f_{\mathrm{r}}\right)$, defined as the fraction of observed radiance that is due to scattering from cloud particles. Errors in cloud OCP become large as $f_{\mathrm{r}}$ approaches zero. The cloud radiance fraction can be estimated within the MLER context (see Eq. 1) using

$f_{\mathrm{r}}=f_{\mathrm{eff}} \frac{I_{\mathrm{cld}}}{I_{\mathrm{obs}}}$.

While $I_{\text {cld }}$ is relatively constant with wavelength (at the wavelengths considered here), $I_{\mathrm{obs}}$ is wavelength dependent owing to variations in Rayleigh scattering and surface albedo. The much brighter Rayleigh scattering background in the UV (as compared with the visible) results in lower values of $f_{\mathrm{r}}$ for the OMI RRS retrievals as compared with those from the $\mathrm{O}_{2}-\mathrm{O}_{2}$ for a given value of $f_{\text {eff }}$. Therefore, we expect greater error amplification for the RRS retrievals at low values of $f_{\text {eff. }}$. Indeed, we observe slightly higher correlations between CloudSat and $\mathrm{OMI} \mathrm{O}_{2}-\mathrm{O}_{2}$ than for Cloudsat versus OMI RRS in the lower $f_{\text {eff }}$ bin. At the wavelengths used for
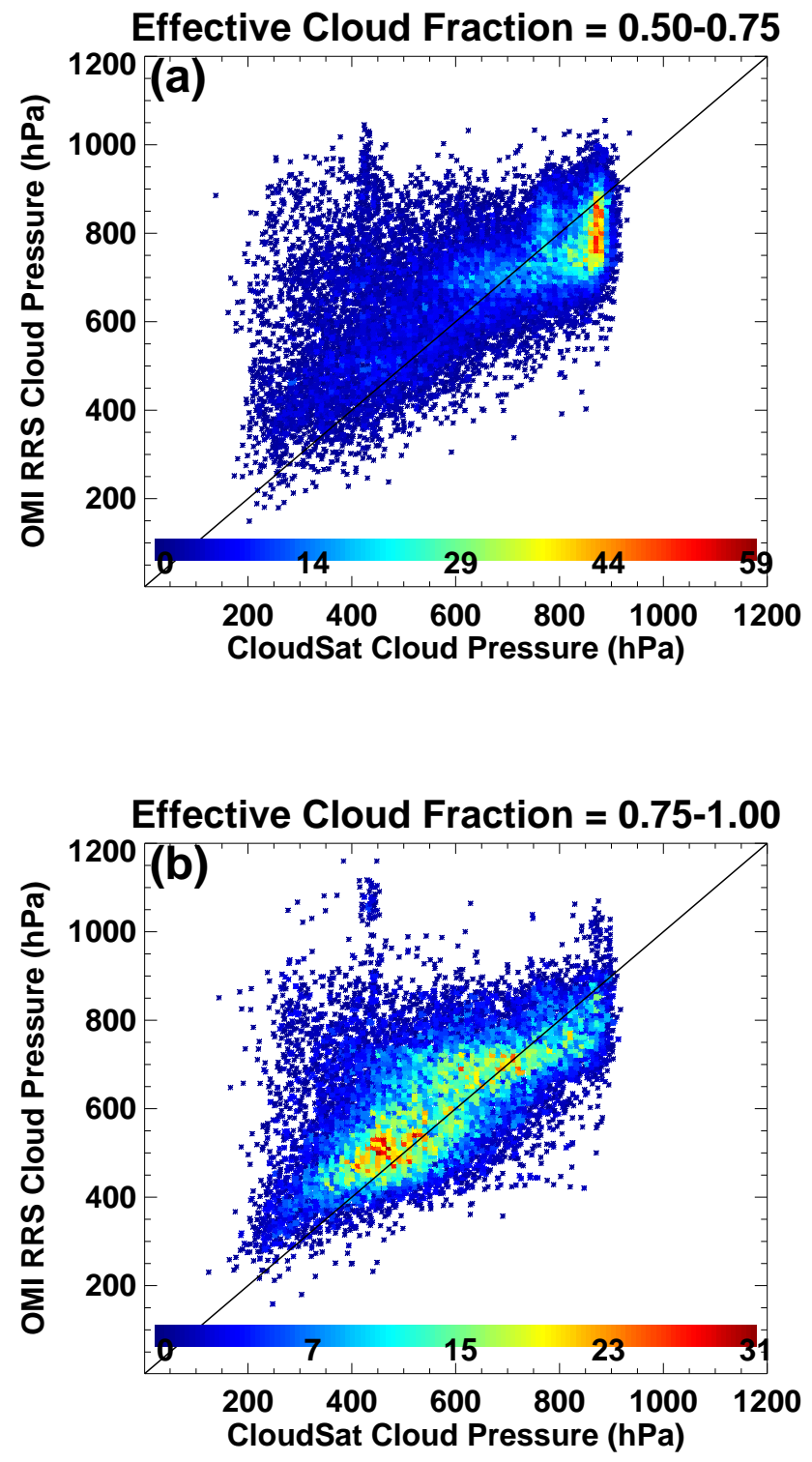

Fig. 9. Similar to Fig. 7 but over ocean (July 2007).

the OMI RRS retrieval, $f_{\mathrm{r}} \simeq 2 f_{\text {eff }}$ for $f_{\text {eff }}<\sim 0.3$. Errors at $f_{\text {eff }}=5 \%$ are thus about an order of magnitude higher than those at $100 \%$. In this paper we focus on data with moderate to high values of cloud radiance fraction.

We next examine the outliers, for which both OMI algorithms are biased high with respect to CloudSat, in more detail. These outliers appear in January (not shown here) as well as the single day in November 2006 that we examined in Fig. 1. A number of these cases appear to be caused by snow-cover that is not correctly identified in the Near Realtime SSM/I EASE-Grid Daily Global Ice Concentration and Snow Extent (NISE) data set (Nolin et al., 1998) used in the OMI algorithms for snow/ice identification. Some of these cases coincide with frontal clouds that may have produced fresh snow that has not yet been identified in the NISE data 

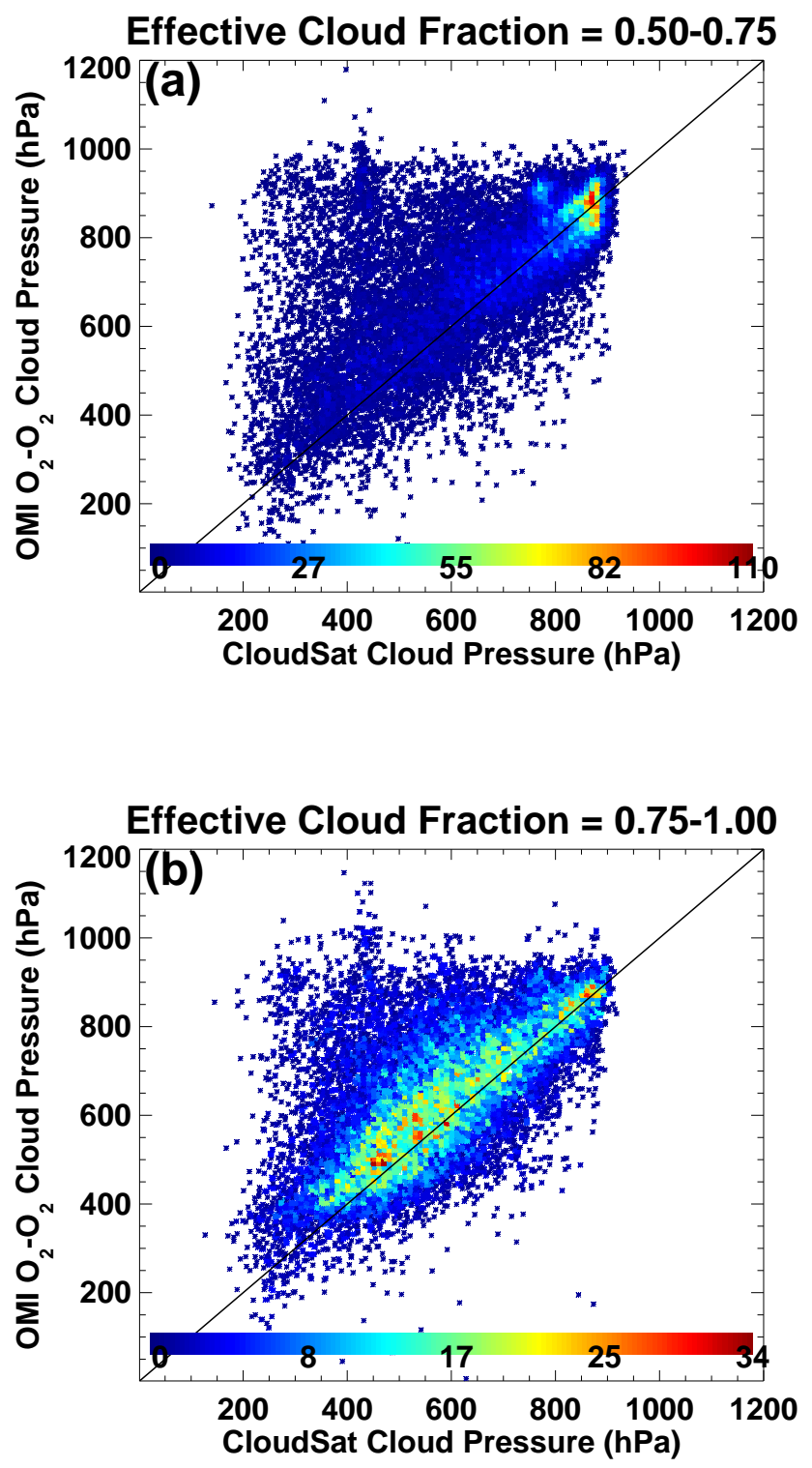

Fig. 10. Similar to Fig. 9 but for $\mathrm{O}_{2}-\mathrm{O}_{2}$ (ocean, July 2007).

set. Analysis of these cases shows that the snow flag is set on subsequent days. We also found a few isolated areas where snow is likely (e.g., northern Canada in winter) and the snow/ice flag is not set, while it is set for the surrounding region.

Not all discrepancies between CloudSat and OMI cloud OCPs occurred near regions of snow-ice. An examination of the CloudSat profiles showed that many of these locations contained multi-layered clouds. As shown in Fig. 6, these are the profiles for which the standard fast simulator has the largest differences with the full RRS simulator. The differences, however, are generally too large to be explained by the fast simulator alone. In many cases, multiple outliers occur within a close proximity where there is significant variability in the CloudSat-simulated cloud OCP as well as cloud-top
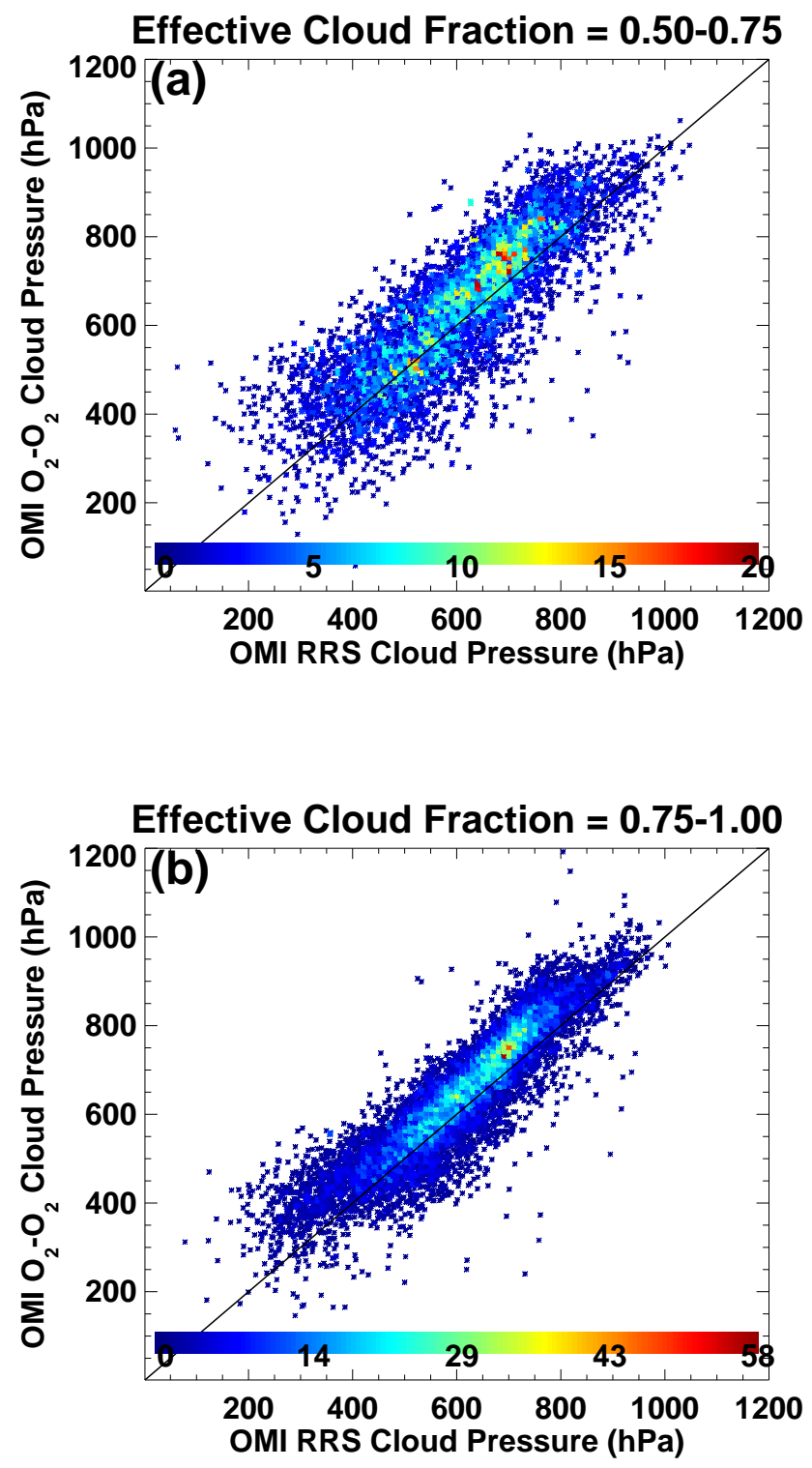

Fig. 11. Similar to Fig. 7 (same sample of observations) but comparing OMI cloud OCP retrievals from the RRS and $\mathrm{O}_{2}-\mathrm{O}_{2}$ products over land (July 2007).

pressure. In most cases, excess scattering and absorption produces higher than expected cloud OCPs in both OMI algorithms, indicating a geophysical effect rather than measurement or algorithm errors. We hypothesize that 3-D cloud effects may be contributing to some of these differences. It is also possible that small-scale features in the CloudSat data are not resolved in the much larger OMI FOV or that the narrow CloudSat slice through the OMI FOV does not fully represent what is seen by OMI. In addition, uncertainties in the CloudSat 2B TAU profiles, e.g., owing to missed low clouds in this product as well as in 2B-GEOPROF-LIDAR (obscured by opaque upper level clouds), may contribute to these differences. 

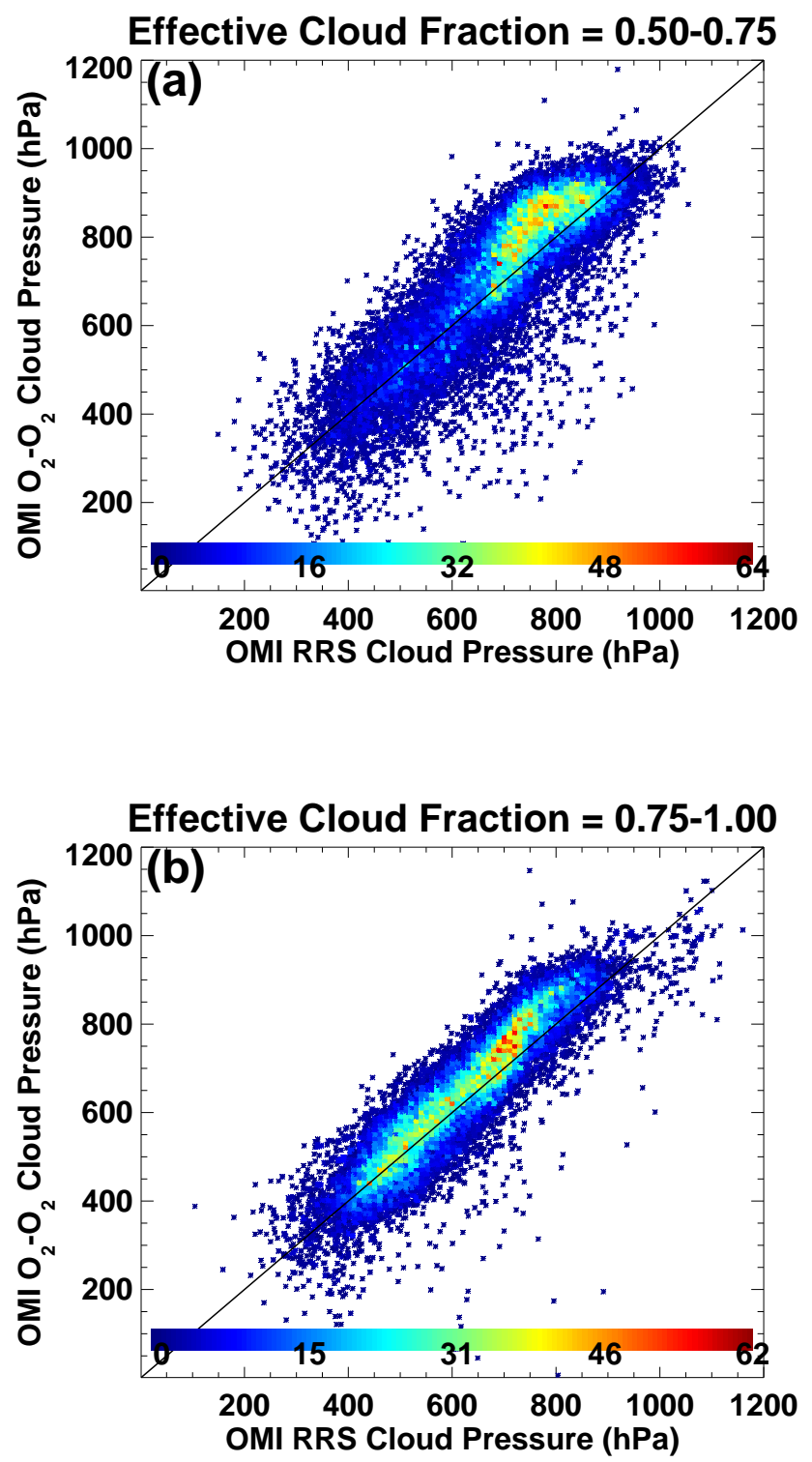

Fig. 12. Similar to Fig. 11 (same sample of observations) but over ocean (July 2007).

\subsection{Comparisons with CloudSat-based fast simulators over ocean}

Figures 9-10 show comparisons similar to those in Figs. 78 , but over ocean. Here, we see a predominance of low altitude (high pressure) clouds for moderate values of $f_{\text {eff }}$. A bimodal distribution in the low clouds with peaks near 775 and $875 \mathrm{hPa}$ is apparent for $f_{\text {eff }}$ between 50 and $75 \%$. This bimodality, a prevalent feature of trade wind cumulus clouds, has been observed in several different passive satellite cloud-top height data sets, both thermal IR and stereo algorithms, as well as surface ceilometer cloud base height measurements (e.g., Genkova et al., 2007; Mote and Frey, 2006). High altitude (low pressure) clouds are prevalent only
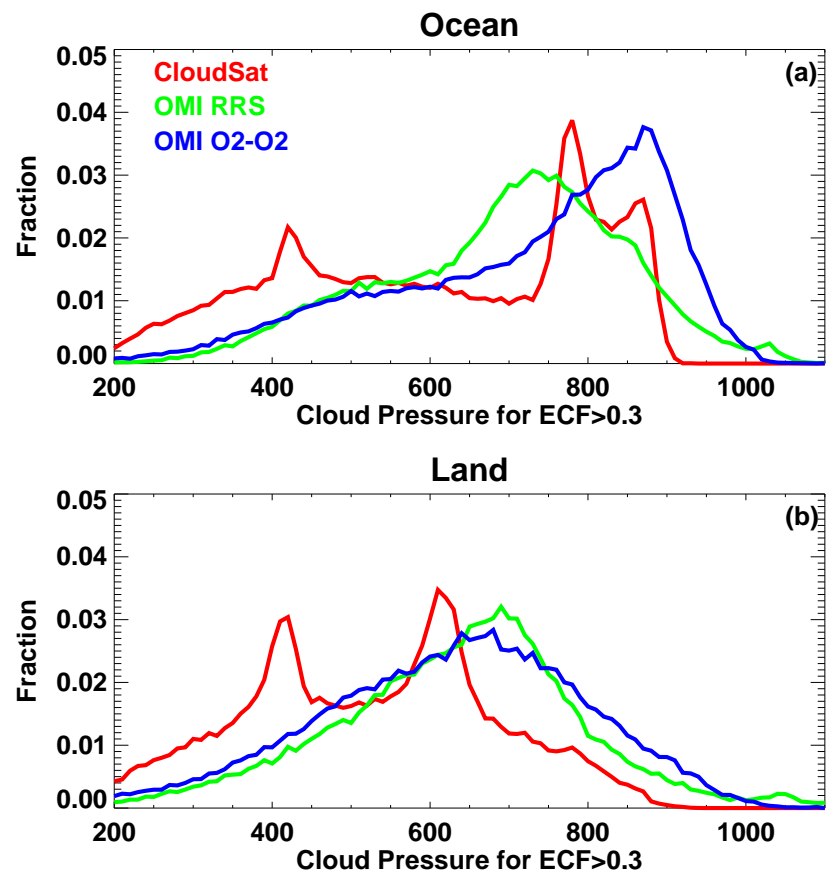

Fig. 13. Probability distribution functions of CloudSat cloud OCP (2B-TAU profiles with fast simulators) and the two OMI cloud algorithms over ocean (a) and land (b) for observations with effective cloud fraction $(\mathrm{ECF})>0.3$.

for high effective cloud fractions. As over land, though not as distinct, for both OMI algorithms we see a cluster of points with a higher cloud OCP than predicted from CloudSat 2BTAU and the fast simulators.

\subsection{Comparisons of two OMI cloud algorithms over land and ocean}

Figures 11 and 12 show similar 2-D histograms for the same sample of observations as above, but now for the OMI RRS versus $\mathrm{O}_{2}-\mathrm{O}_{2}$ cloud OCPs over land and ocean, respectively. The $\mathrm{O}_{2}-\mathrm{O}_{2}$ OCPs are slightly higher than those from RRS retrievals on average. The distributions are skewed, particularly over ocean where the $\mathrm{O}_{2}-\mathrm{O}_{2}$ algorithm provides higher cloud OCPs than those from the RRS algorithm.

The scatter between the two OMI cloud OCPs is significantly smaller than either one compared with CloudSat. The OMI algorithms are nearly independent; they operate on different physical principles and use two separate detectors. Therefore, our results strongly indicate that consistent differences between CloudSat and both OMI cloud OCPs are not due to algorithm or measurement error but rather to geophysical effects, such as cloud 3-D effects. Marshak et al. (1998) showed only slight enhancements to column absorption resulting from horizontal fluxes. Kokhanovsky et al. (2007a) showed that cloud 3-D effects were important for the determination of cloud optical thickness based on absolute 

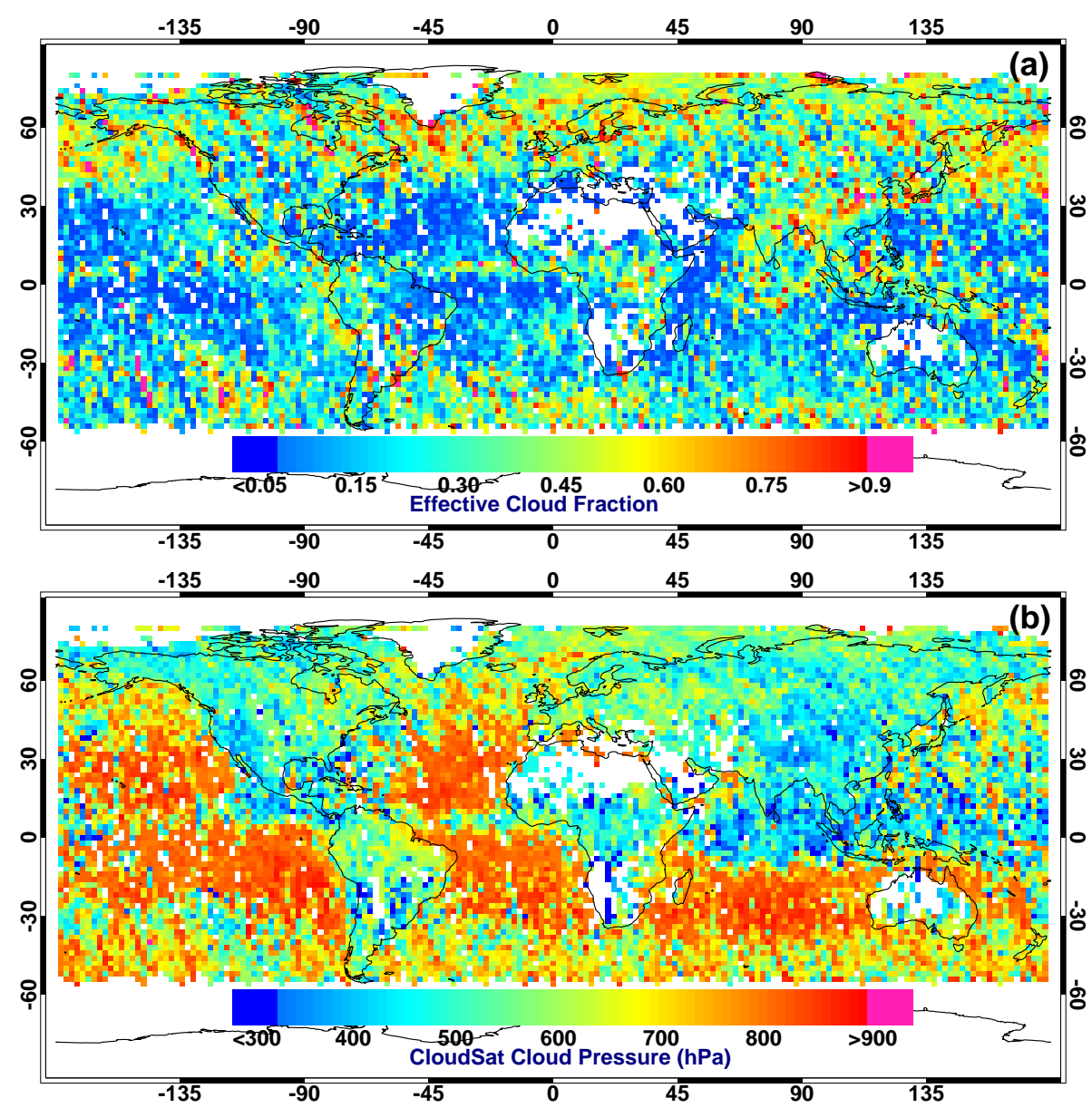

Fig. 14. Maps of gridded effective cloud fraction from the OMI cloud RRS algorithm (a) and cloud OCP from CloudSat (b) for July 2007.

reflectance values, while there was only a slight sensitivity of cloud pressure retrievals in the oxygen A-band to cloud 3-D effects. However, they simulated only a few scenarios. The cloud adjacency effect (Marshak et al., 2008) may be important for OMI cloud OCP retrievals.

\subsection{Probability Distribution Functions (PDFs) of cloud OCP}

Figure 13 shows cloud OCPs from OMI and CloudSat (standard weighting) for July 2007 displayed as probability distribution functions (PDFs) for both land and ocean and derived using only observations with $f_{\text {eff }}>0.3$. The OMI distributions are similar to those shown previously by Sneep et al. (2008). Over ocean, CloudSat shows a trimodal distribution with a small peak near $400 \mathrm{hPa}$. Both OMI algorithms only hint at a low pressure mode, with a higher pressure than that given by CloudSat. As noted earlier for high pressure clouds, there are peaks in the distribution near 775 and $875 \mathrm{hPa}$ in the CloudSat-derived OCPs. The OMI RRS algorithm underestimates the pressure of these clouds while the OMI $\mathrm{O}_{2}-\mathrm{O}_{2}$ algorithm overestimates. Neither OMI cloud algorithm shows a clear bimodal distribution in the high pressure clouds, though there is a hint of bimodality in the OMI RRS PDF. Genkova et al. (2007) showed that distributions of cloud top heights of trade wind cumulus derived from thermal IR measurements are affected by spatial resolution. It should be noted that the OMI FOV is twice as wide in the cross-track direction as the length along track over which the CloudSat OCPs are averaged.

Over land, the CloudSat OCP PDF is bimodal with peaks near 400 and $600 \mathrm{hPa}$. Similar bimodal distributions of cloud top pressure and vertical structure have been shown with both active and passive sounding data as well as in general circulation model output (e.g., Chang and Li, 2005a,b; Comstock and Jakob, 2004; Mote and Frey, 2006; Xi et al., 2010). Neither OMI algorithm produces a bimodal distribution; both produce a single peak between 650 and $700 \mathrm{hPa}$. The RRS $\mathrm{PDF}$ is more sharply peaked, while the $\mathrm{O}_{2}-\mathrm{O}_{2}$ produces more high pressure clouds. 

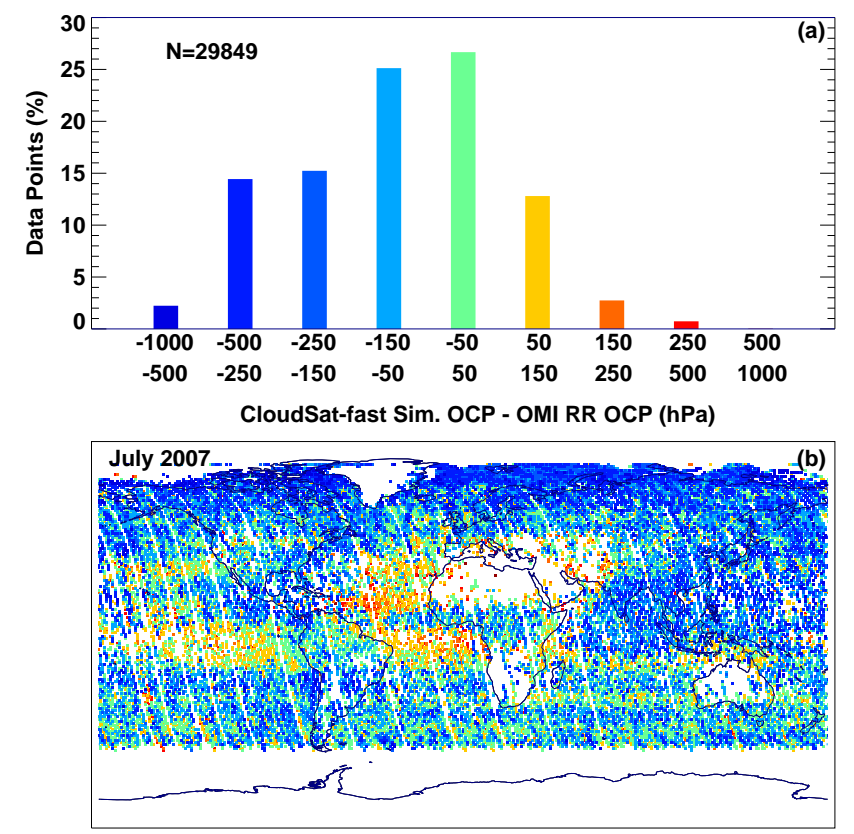

Fig. 15. Histogram (a) and color-coded map (b) of differences between CloudSat cloud OCP and that from the OMI RRS algorithm for effective cloud fractions $>0.1$.

\subsection{Maps of cloud OCP and effective cloud fraction}

Figure 14 shows gridded maps of $f_{\text {eff }}$ from the OMI RRS algorithm and cloud OCP from CloudSat for the observations collocated with CloudSat in July 2007. This provides a context for maps of the differences between CloudSat-based OCPs and those from OMI RRS and $\mathrm{O}_{2}-\mathrm{O}_{2}$, respectively, shown in Figs. 15 and 16. These figures also show corresponding histograms. The difference maps show all individual points (i.e., not gridded data). Each point is color-coded by the corresponding histogram bin. Note that we include all observations with $f_{\text {eff }}$ as low as 0.1 ; at these low values of $f_{\text {eff, }}$ error amplification can be substantial and is larger for the OMI RRS results than for $\mathrm{O}_{2}-\mathrm{O}_{2}$.

In the histograms, the skewed distributions are seen here for both OMI algorithms versus CloudSat over land and ocean as shown in previous figures. The maps provide the geographic distribution of the differences. It is now apparent that most of the positive differences (CloudSat OCPs higher than OMI) over ocean occur in regions where subsidence produces low clouds and relatively low values of $f_{\text {eff. }}$ The OMI RRS algorithm produces larger positive differences in these regions than the $\mathrm{O}_{2}-\mathrm{O}_{2}$. The high cloud OCPs seen in the inter-tropical convergence zone (ITCZ) show mostly negative differences (Cloudsat OCPs lower than those from both OMI algorithms). Some differences between OMI algorithms are seen such as over the Pacific at low latitudes where Joiner et al. (2010) showed that large numbers of OMI FOVs contain multi-layer clouds. Finally,
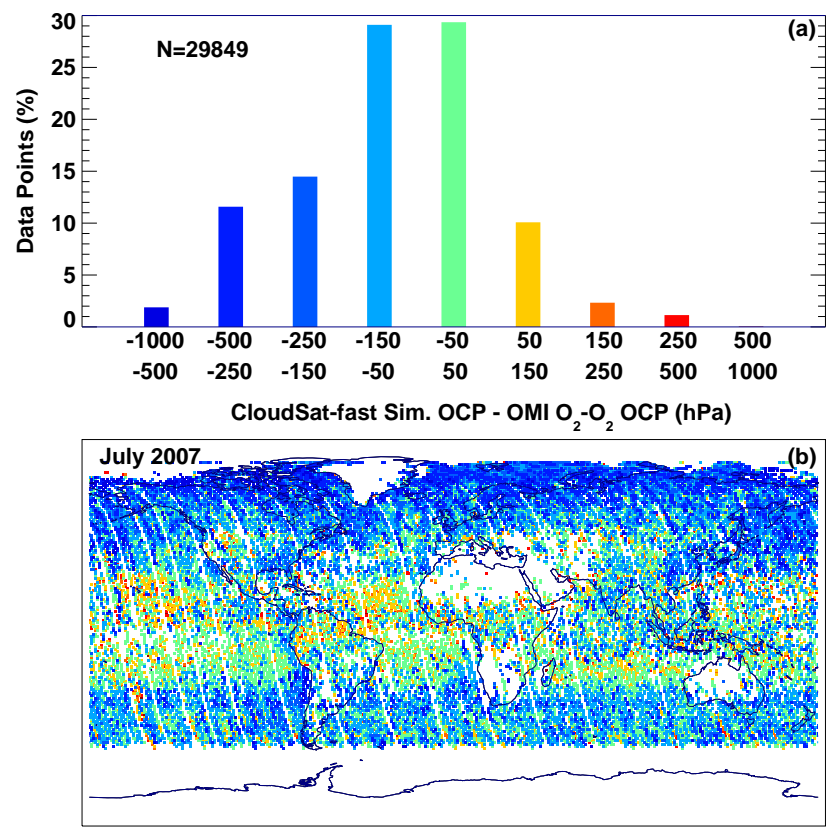

Fig. 16. Similar to Fig. 15, but for $\mathrm{OMI} \mathrm{O}_{2}-\mathrm{O}_{2}$.

we note alternating patterns of differences between CloudSat and OMI RRS with latitude at the high southern latitudes where solar zenith angles are highest. This may indicate some residual errors in the look-up table interpolation scheme. Such patterns are muted in the $\mathrm{O}_{2}-\mathrm{O}_{2}$ results that have been recently updated with more nodes added to the table look-up scheme.

We also examined data for January 2007. The spatial patterns of differences with CloudSat are similar to July in the tropics. At moderate to high latitudes, the patterns have reversed with respect to the hemispheres. Comparison of the differences in both July and January 2007 are qualitatively consistent with those expected from missed low clouds that are maximum in the summer hemisphere at moderate to high latitudes as shown by Stephens et al. (2008).

\section{Conclusions}

We have developed a relatively simple scheme for simulating retrieved cloud optical centroid pressures from satellite solar backscatter observations. We compared fast simulator results with those from a detailed retrieval simulator that more fully accounts for the complex radiative transfer in a cloudy atmosphere; agreement is reasonable between the two. We also showed several examples of weighting functions for the cloud OCP.

We used the fast simulators to conduct a comprehensive evaluation of cloud OCPs from the two OMI algorithms using collocated CloudSat and Aqua MODIS data, a unique situation afforded by the A-train constellation of satellites. 
We find that both OMI algorithms perform reasonably well, and that the two algorithms agree better with each other than either does with the collocated CloudSat data. This indicates that patchy snow/ice, cloud 3-D effects, and/or uncertainties both in the CloudSat 2B-TAU profiles and fast simulators are affecting comparisons with both OMI products similarly.

Our fast simulators may be used to simulate cloud OCP from output generated by general circulation models (GCM) with appropriate account of cloud overlap. We have implemented such a scheme and plan to compare OMI data with GCM output in the near future. Fast simulators are also ideal for assimilation of satellite-derived OCPs where computational efficiency is important. For these applications, uncertainties and errors in both the fast simulators and OMI OCP retrievals must be accounted for. This work provides a basis for estimating those uncertainties.

Acknowledgements. This material is based upon work supported by the National Aeronautics and Space Administration under agreement NNH10ZDA001N-AURA issued through the Science Mission Directorate for the Aura Science Team managed by Kenneth Jucks and Richard Eckman. We thank the OMI, MODIS, and CloudSat data processing teams for providing the data used for this study. We thank the two anonymous reviewers whose comments led to improvements in the final version of the manuscript and associate editor Bernhard Mayer. The lead author thanks Arlindo da Silva for helpful discussions that include coining the term "optical centroid pressure".

Edited by: B. Mayer

\section{References}

Acarreta, J. R., de Haan, J. F., and Stammes, P.: Cloud pressure retrieval using the $\mathrm{O}_{2}-\mathrm{O}_{2}$ absorption band at $477 \mathrm{~nm}$, J. Geophys. Res., 109, D05204, doi:10.1029/2003JD003915, 2004.

Ahmad, Z., Bhartia, P. K., and Krotkov, N.: Spectral properties of backscattered UV radiation in cloudy atmospheres, J. Geophys. Res., 109, D01201, doi:10.1029/2003JD003395, 2004.

Baum, B. A., Yang, P., Heymsfield, A. J., Platnick, S., King, M. D., $\mathrm{Hu}$, Y. X., and Bedka, S. T.: Bulk scattering models for the remote sensing of ice clouds, Part 2: Narrowband models, J. Appl. Meteorol., 44, 1896-1911, 2005.

Bovensmann, H., Burrows, J., Buchwitz, M., Frerick, J., Noel, S., Rozanov, V., Chance, K., and Goede, A.: SCIAMACHY: mission objectives and measurement modes, J. Atmos. Sci., 56, 127-150, 1999.

Boersma, K. F., Eskes, H. J., and Brinksma, E. J.: Error analysis for tropospheric $\mathrm{NO}_{2}$ retrieval from space, J. Geophys. Res., 109, D04311, doi:10.1029/2003JD003962, 2004.

Bucsela, E. J., Celarier, E. A., Wenig, M. O., Gleason, J. F., Veefkind, J. P., Boersma, K. F., and Brinksma, E. J.: Algorithm for $\mathrm{NO}_{2}$ vertical column retrieval from the Ozone Monitoring Instrument, IEEE T. Geosci. Remote, 44, 1245-1258, 2006.

Burrows, J. P., Weber, M., Buchwitz, M., Rozanov, V., LadstatterWeissenmayer, A., Richter, A., deBeek, R., Hoogen, R., Bramstedt, K., Eichmann, K.-U., Eisinger, M., and Perner, D.: The
Global Ozone Monitoring Experiment (GOME): Mission concept and first scientific results, J. Atmos. Sci., 56, 151-175, 1999.

Chang F.-L. and Li, Z.: A new method for detection of cirrus overlapping water clouds and determination of their optical properties, J. Atmos. Sci., 62, 3993-4009, 2005a.

Chang F.-L. and Li, Z.: A near-global climatology of single-layer and overlapped clouds and their optical properties retrieved from Terra/MODIS data using a new algorithm, J. Climate, 18, 45724771, 2005b.

CloudSat Project: Level 2 cloud optical depth product process description and interface control document, version 5.0, available at: http://www.cloudsat.cira.colostate.edu/ICD/2B-TAU/ 2B-TAU_PDICD_5.0.pdf, last access: 4 October 2011, Colorado State University, Fort Collins, CO, USA, 2008.

Coakley, J. A. and Chylek, P.: The two-stream approximation in the radiative transfer: Including the angle of incident radiation, J. Atmos. Sci., 32, 409-418, 1975.

Coldewey-Egbers, M., Weber, M., Lamsal, L. N., de Beek, R., Buchwitz, M., and Burrows, J. P.: Total ozone retrieval from GOME UV spectral data using the weighting function DOAS approach, Atmos. Chem. Phys., 5, 1015-1025, doi:10.5194/acp5-1015-2005, 2005.

Comstock, J. M. and Jakob, C.: Evaluation of tropical cirrus cloud properties derived from ECMWF model output and ground based measurements over Nauru Island, Geophys. Res. Lett., 31, L10106, doi:10.1029/2004GL019539, 2004.

Cox, C. and Munk, W.: Measurement of the roughness of the sea surface from photographs of the Sun's glitter, J. Opt. Soc. Am., 44, 838-850, 1954.

Daniel, J. S., Solomon, S., Miller, H. L., Langford, A. O., Portmann, R. W., and Eubank, C. S.: Retrieving cloud information from passive measurements of solar radiation absorbed by molecular oxygen and $\mathrm{O}_{2}-\mathrm{O}_{2}$, J. Geophys. Res., 108, 4515, doi:4510.1029/2002JD002994, 2003.

Deirmendjian, D.: Electromagnetic scattering on spherical polydispersions, Elsevier Sci., New York, 290 pp., 1969.

Dubuisson, P., Frouin, R., Dessailly, D., and Duforet, L,: Altitude of aerosol plumes over the ocean from reflectance ratio measurements in the $\mathrm{O}_{2}$ A-band, Remote Sens. Environ., 113, 1899 1911, 2009.

Ferlay, N., Thieuleux, F., Cornet, C., Davis, A. B., Dubuisson, P., Ducos, F., Parol, F., Riédi, J., and Vanbauce, C.: Toward New Inferences about Cloud Structures from Multidirectional Measurements in the Oxygen A Band: Middleof-Cloud Pressure and Cloud Geometrical Thickness from POLDER-3/PARASOL, J. Appl. Meteorol. Clim., 49, 2492 2507, doi:10.1175/2010JAMC2550.1, 2010.

Genkova, I., Seiz, G., Zuidema, P., Zhao, G., and Di Girolamo, L.: Cloud top height comparisons from ASTER, MISR, and MODIS for trade wind cumuli, Remote Sens. Environ., 107, 211-222, 2007.

Joiner, J. and Bhartia, P. K.: Accurate Determination of Total Ozone using SBUV Continuous Spectral Scan Measurements, J. Geophys. Res., 102, 12957-12969, 1995.

Joiner, J. and Vasilkov, A. P.: First results from the OMI rotational raman scattering cloud pressure algorithm, IEEE T. Geosci. Remote, 44, 1272-1282, 2006.

Joiner, J., Vasilkov, A. P., Flittner, D. E., Gleason, J. F., and Bhartia, P. K.: Retrieval of cloud chlorophyll content using Raman 
scattering in GOME spectra, J. Geophys. Res., 109, D01109, doi:10.1029/2003JD003698, 2004.

Joiner, J., Vasilkov, A. P., Yang, K., and Bhartia, P. K.: Total column ozone over hurricanes from the ozone monitoring instrument, Geophys. Res. Lett., 33, L06807, doi:10.1029/2005GL025592, 2006.

Joiner, J., Schoeberl, M. R., Vasilkov, A. P., Oreopoulos, L., Platnick, S., Livesey, N. J., and Levelt, P. F.: Accurate satellitederived estimates of the tropospheric ozone impact on the global radiation budget, Atmos. Chem. Phys., 9, 4447-4465, doi:10.5194/acp-9-4447-2009, 2009.

Joiner, J., Vasilkov, A. P., Bhartia, P. K., Wind, G., Platnick, S., and Menzel, W. P.: Detection of multi-layer and vertically-extended clouds using A-train sensors, Atmos. Meas. Tech., 3, 233-247, doi:10.5194/amt-3-233-2010, 2010.

Joseph, J. H., Wiscombe, W. J., and Weinman, J. A.: The delta-Eddington approximation for radiative flux transfer, J. Atmos. Sci., 33, 2452-2459, 1976.

Koelemeijer, R. B. A. and Stammes, P.: Effects of clouds on ozone column retrieval from GOME UV measurements, J. Geophys. Res., 104, 8281-8294, 1999.

Koelemeijer, R. B. A., Stammes, P., Hovenier, J. W., and de Haan, J. F.: A fast method for retrieval of cloud parameters using oxygen A-band measurements from the Global Ozone Monitoring Experiment, J. Geophys. Res., 106, 3475-3496, 2001.

Koelemeijer, R. B. A., Stammes, P., Hovenier, J. W., and de Haan, J. F.: Global distribution of effective cloud fraction and cloud top pressure derived from oxygen A band measured by the Global Ozone Monitoring Experiment: Comparison to ISCCP data, J. Geophys. Res., 107, 4151, doi:10.1029/2001JD000840, 2002.

Kokhanovsky, A. A., Rozanov, V. V., Nauss, T., Reudenbach, C., Daniel, J. S., Miller, H. L., and Burrows, J. P.: The semianalytical cloud retrieval algorithm for SCIAMACHY I, The validation, Atmos. Chem. Phys., 6, 1905-1911, doi:10.5194/acp-6-1905-2006, 2006.

Kokhanovsky, A. A., Mayer, B., Rozanov, V. V., Wapler, K., Burrows, J. P., and Schumann, U.: The influence of broken cloudiness on cloud top height retrievals using the nadir observations of backscattered solar radiation in the oxygen A-band, J. Quant. Spectrosc. Ra., 103, 460-477, 2007a.

Kokhanovsky, A. A., Mayer, B., Rozanov, V. V., Wapler, K., Lamsal, L. N., Weber, M., Burrows, J. P., and Schumann, U.: Satellite ozone retrieval under broken cloud conditions: An error analysis based on Monte Carlo simulations, IEEE T. Geosci. Remote, 45, 187-194, 2007b.

L'Ecuyer, T. S., Wood, N. B., Haladay, T., Stephens, G. L., and Stackhouse Jr., P. W.: Impact of clouds on atmospheric heating based on the R04 CloudSat fluxes and heating rates data set, J. Geophys. Res., 113, D00A15, doi:10.1029/2008JD009951, 2008.

Levelt, P. F., van der Oord, G. H. J., Dobber, M. R., Malkki, A., Visser, H., de Vries, J., Stammes, P., Lundell, J. O. V., and Saari, H.: The ozone monitoring instrument, IEEE T. Geosci. Remote, 44, 1093-1101, 2006.

Mace, G. G., Zhang, Q., Vaughan, M., Marchand, R., Stephens, G., Trepte, C., and Winker, D.: A description of hydrometeor layer occurrence statistics derived from the first year of merged Cloudsat and CALIPSO data, J. Geophys. Res., 114, D00A26, doi:10.1029/2007JD009755, 2009.
Marshak, A., Davis, A., Wiscombe, W., Ridgway, W., and Cahalan, R.: Biases in shortwave column absorption in the presence of fractal clouds, J. Climate, 11, 431-446, 1998.

Marshak, A., Wen, G., Coakley, J. A., Remer, L. A., Loeb, N. G., and Cahalan, R. F.: A simple model for the cloud adjacency effect and the apparent bluing of aerosols near clouds, J. Geophys. Res., 113, D14S17, doi:10.1029/2007JD009196, 2008.

McPeters, R. D., Bhartia, P. K., Krueger, A. J., Herman, J. R., Schlesinger, B. M., Wellemeyer, C. G., Seftor, C. J., Jaross, G., Taylor, S. L., Swissler, T., Torres, O., Labow, G., Byerly, W., and Cebula, R. P.: Nimbus-7 Total Ozone Mapping Spectrometer (TOMS) data products user's guide, NASA Ref. Pub. 1384, Washington, DC, USA, 67 pp., 1996.

Meador, W. E. and Weaver, W. R.: Two-stream approximation to radiative transfer in planetary atmospheres: A unified description of existing methods and a new improvement, J. Atmos. Sci., 37, 630-643, 1980.

Menzel, W. P., Frey, R., Zhang, H., Wylie, D. P., Moeller, C., Holz, R., Maddux, B., Baum, B. A., Strabala, K. I., and Gumley, L.: MODIS global cloud-top pressure and amount estimation: algorithm description and results, J. Appl. Meteorol. Clim., 47, 1175-1198, 2008.

Mote, P. W. and Frey, R.: Variability of clouds and water vapor in low latitudes: View from Moderate Resolution Imaging Spectroradiometer (MODIS), J. Geophys. Res., 111, D16101, doi:10.1029/2005JD006791, 2006.

Munro, R., Eisinger, M., Anderson, C., Callies, J., Corpaccioli, E., Lang, R., Lefebvre, A., Livschitz, Y., and Perez Albinana, A.: GOME-2 on Metop: from in-orbit verification to routine operations, in: Proceedings of EUMETSAT Meteorological Satellite Conference, Helsinki, Finland, 12-16 June 2006.

Nolin, A., Armstrong, R. L., and Maslanik, J.: Near Real-Time SSM/I EASE-Grid Daily Global Ice Concentration and Snow Extent, January to March 2004 (updated daily), National Snow and Ice Data Center, Digital media, Boulder, CO, USA, 1998.

Reuter, M., Buchwitz, M., Schneising, O., Heymann, J., Bovensmann, H., and Burrows, J. P.: A method for improved SCIAMACHY $\mathrm{CO}_{2}$ retrieval in the presence of optically thin clouds, Atmos. Meas. Tech., 3, 209-232, doi:10.5194/amt-3-209-2010, 2010.

Rozanov, V. V. and Kokhanovsky, A. A.: Semianalytical cloud retrieval algorithm as applied to the cloud top altitude and the cloud geometrical thickness determination from top-of-atmosphere reflectance measurements in the oxygen A band, J. Geophys. Res., 109, D05202, doi:10.1029/2003JD004104, 2004.

Rozanov, V. V., Kokhanovsky, A. A., and Burrows, J. P: The determination of cloud altitudes using GOME reflectance spectra: multilayered cloud systems, IEEE T. Geosci. Remote, 42, 1009 1017, 2004.

Sneep, M., de Haan, J., Stammes, P., Wang, P., Vanbauce, C., Joiner, J., Vasilkov, A. P., and Levelt, P. F.: Three way comparison between OMI/Aura and POLDER/PARASOL cloud pressure products, J. Geophys. Res., 113, D15S23, doi:10.1029/2007JD008694, 2008.

Spurr, R. J. D., de Haan, J., van Oss, R., and Vasilkov, A. P.: Discrete ordinate radiative transfer in a stratified medium with first order rotational Raman scattering, J. Quant. Spectrosc. Ra., 109, 404-425, 2008. 
Stammes, P., Sneep, M., de Haan, J. F., Veefkind, J. P., Wang, P., and Levelt, P. F.: Effective cloud fractions from the Ozone Monitoring Instrument: Theoretical framework and validation, J. Geophys. Res., 113, D16S38, doi:10.1029/2007JD008820, 2008.

Stephens, G. L., Vane, D. G., Taneli, S., Im, E., Durden, S., Rokey, M., Reike, D., Partain, P., Mace, G. G., Austin, R., L'Ecuyer, T., Haynes, J., Lebsock, M., Suzuki, K., Waliser, D., Wu, D., Kay, J., Gettleman, A., Wang, Z., and Marchand, R.: CloudSat Mission: Performance and early science after the first year of operation, J. Geophys. Res., 113, D00A18, doi:10.1029/2008JD009982, 2008.

van Roozendael , M., Loyola, D., Spurr, R., Balis, D., Lambert, J.-C., Livschitz, Y., Valks, P., Ruppert, T., Kenter, P., Fayt, C., and Zehner, C.: Ten years of GOME/ERS-2 total ozone data-The new GOME data processor (GDP) version 4: 1. Algorithm description, J. Geophys. Res., 111, D14311, doi:10.1029/2005JD006375, 2006.

Vanbauce, C., Cadet, B., and Marchand, R. T.: Comparison of POLDER apparent and corrected oxygen pressure to ARM/MMCR cloud boundary pressures, Geophys. Res. Lett., 3, 1212, doi:10.1029/2002GL016449, 2003.

Vasilkov, A. P., Joiner, J., Yang, K., and Bhartia, P. K.: Improving total column ozone retrievals by using cloud pressures derived from Raman scattering in the UV, Geophys. Res. Lett., 31, L20109, doi:10.1029/2004GL020603, 2004.
Vasilkov, A. P., Joiner, J., Spurr, R., Bhartia, P. K., Levelt, P. F., and Stephens, G.: Evaluation of the OMI cloud pressures derived from rotational Raman scattering by comparisons with other satellite data and radiative transfer simulations, J. Geophys. Res., 113, D15S19, doi:10.1029/2007JD008689, 2008.

Vasilkov, A. P., Joiner, J., Oreopoulos, L., Gleason, J. F., Veefkind, P., Bucsela, E., Celarier, E. A., Spurr, R. J. D., and Platnick, S.: Impact of tropospheric nitrogen dioxide on the regional radiation budget, Atmos. Chem. Phys., 9, 6389-6400, doi:10.5194/acp-96389-2009, 2009.

Veefkind, J. P., de Haan, J. F., Brinksma, E. J., Kroon, M., and Levelt, P.: Total ozone from the Ozone Monitoring Instrument (OMI) using the DOAS technique, IEEE T. Geosci. Remote, 44, 1239-1244, 2006.

Xi, B., Dong, X., Minnis, P., and Khaiyer, M. M.: A 10 year climatology of cloud fraction and vertical distribution derived from both surface and GOES observations over the DOE ARM SPG site, J. Geophys. Res., 115, D12124, doi:1029/2009JD012800, 2010.

Ziemke, J. R., Joiner, J., Chandra, S., Bhartia, P. K., Vasilkov, A., Haffner, D. P., Yang, K., Schoeberl, M. R., Froidevaux, L., and Levelt, P. F.: Ozone mixing ratios inside tropical deep convective clouds from OMI satellite measurements, Atmos. Chem. Phys., 9, 573-583, doi:10.5194/acp-9-573-2009, 2009. 